Title page

\title{
The African Surgical Outcomes Study: a 7-day prospective observational cohort study
}

Bruce M Biccard, ${ }^{1}$ Thandinkosi E Madiba, ${ }^{2}$ Hyla-Louise Kluyts, ${ }^{3}$ Dolly M Munlemvo, ${ }^{4}$ Farai Madzimbamuto, ${ }^{5}$ Apollo Basenero, ${ }^{6}$ Christina S Gordon, ${ }^{7}$ Coulibaly Youssouf, ${ }^{8}$ Sylvia Rakotoarison, ${ }^{9}$ Veekash Gobin, ${ }^{10}$ ALS Samateh, ${ }^{11}$ Chaibou M Sani, ${ }^{12}$ AO Omigbodun, ${ }^{13}$ Simbo D Amanor-Boadu, ${ }^{14}$ Janat Tumukunde, ${ }^{15}$ Tonya M Esterhuizen, ${ }^{16}$ Yannick Le Manach, ${ }^{17}$ Patrice Forget, ${ }^{18}$ Abdulaziz M Elkhogia, ${ }^{19}$ RM Mehyaoui, ${ }^{20}$ Eugene Zoumeno, ${ }^{21}$ Gabriel Ndayisaba, ${ }^{22}$ Henry Ndasi, ${ }^{23}$ Andrew Ndonga, ${ }^{24}$ Zipporah Ngumi, ${ }^{25}$ Ushmah Patel, ${ }^{26}$ Daniel Zemenfes Ashebir, ${ }^{27}$ Akwasi AntwiKusi, ${ }^{28}$ Bernard Mbwele, ${ }^{29}$ Hamza Doles Sama, ${ }^{30}$ Mahmoud Elfiky, ${ }^{31}$ Maher Fawzy, ${ }^{32}$ Rupert M Pearse, ${ }^{33}$ on behalf of the African Surgical Outcomes Study (ASOS) investigators.*

\section{*See ASOS Investigators Appendix}

1. Prof BM Biccard PhD, Professor $\dagger$ and $2^{\text {nd }}$ Chair, Department of Anaesthesia and Perioperative Medicine, Groote Schuur Hospital, Faculty of Health Sciences, University of Cape Town, South Africa

2. Prof TE Madiba PhD, Professor $\uparrow$ and Head, Department of Surgery, University of KwaZulu-Natal, South Africa

3. Prof H Kluyts MMed (Anaes), Department of Anaesthesiology, University of Pretoria, South Africa

4. Dr Dolly M Munlemvo, Specialist in Anaesthesiology, University Hospital of Kinshasha, Democratic Republic of Congo

5. Dr FD Madzimbamuto FCA (ECSA), Senior Lecturer, Department of Anaesthesia and Critical Care Medicine, University of Zimbabwe College of Health Sciences, Mazowe St, Belgravia, Box A178, Avondale, Harare, Zimbabwe

6. Dr A Basenero MBChB, Ministry of Health and Social Services Namibia, Private Bag 13198, Windhoek, Namibia, Namibia

7. Ms CS Gordon, Quality Assurance Manager, Ministry of Health and Social Services, Namibia

8. Prof Coulibaly Youssouf, Professor and Chief of Department, Faculté de médicine de Bamako, Mali

9. Dr SR Rakotoarison, Geneticist, LOT II M 46 R, Androhibe, Tana 101, Madagascar

10. Dr V Gobin, Ministry of Health and Quality of Life, Jawaharlal Nehru Hospital (JNH), Rose Belle, Mauritius

11. Dr ALS Samateh FWACS, Head of Department of Surgery, Edward Francis Small Teaching Hospital, Banjul, The Gambia 
12. Dr Chaibou M Sani, Anaesthesiologist and Chief of Department of Anesthesiology, Intensive Care and Emergency, National Hospital of Niamey, Republic of Niger

13. Prof AO Omigbodun FWACS, Professor of Obstetrics and Gynaecology, College of Medicine, University of Ibadan, Nigeria

14. Prof Simbo D Amanor-Boadu, Professor, Department of Anaesthesia, University College Hospital, Ibadan, Nigeria

15. Dr JT Tumukunde MMed (Anaesthesia), Anaesthesiologist, Makerere University, Kampala, Uganda Masters in Medicine (Anaesthesia), Uganda

16. TM Esterhuizen MSc (Epidemiology), Biostatistician, Centre for Evidence Based Health Care, Stellenbosch University, South Africa

17. Yannick Le Manach, Ph.D. Departments of Anesthesia \& Clinical Epidemiology and Biostatistics, Michael DeGroote School of Medicine, Faculty of Health Sciences, McMaster University and Population Health Research Institute, David Braley Cardiac, Vascular and Stroke Research Institute, Perioperative Medicine and Surgical Research Unit, Hamilton, Ontario, Canada.

18. Prof P Forget MD PhD, Vrije Universiteit Brussel (VUB), Universitair Ziekenhuis Brussel (UZ Brussel), Anesthesiology and Perioperative Medicine, Laarbeeklaan 101, 1090 Brussels, Belgium

19. Dr AM Elkhogia FRCA, Senior Consultant and Head of Anaesthesia Department, Tripoli Medical Centre, Tripoli, Libya

20. Prof RM Mehyaoui, Hospital of Cardiovasculaire Pathology, Universitar Hospital, Algeria

21. Professor E Zoumeno, Faculté des Sciences de la Santé de Cotonou, Hôpital de la mère et de l'enfant, Lagune de Cotonou, Benin

22. Prof Gabriel Ndayisaba, Kamenge Teaching Hospital, Head of Department of Surgery, Bujumbura, Burundi

23. Dr Henry Ndasi, DS, FCS Department of Orthopaedics and General Surgery, Baptist Hospital, Mutengene, Cameroon

24. Dr Andrew KN Ndonga FICS, General and Gastrosurgery, Mater Hospital, Kenya

25. Prof ZWW Ngumi FFARCS, Chair Department of Anaesthesia, University of Nairobi School of Medicine, Kenya

26. Dr UP Patel MMed (Anaes), Anaesthesiologist, University Teaching Hospital, Lusaka, Zambia

27. Prof Daniel Z Ashebir, Depart of Surgery, School of Medicine, CHS, Addis Ababa University, Ethiopia

28. Dr AAK Antwi-Kusi, FGCS, Senior Lecturer, Department of Anaesthesiology and Intensive Care, School of Medical Sciences, College of Health Sciences, Kwame Nkrumah University of Science and Technology, Kumasi, Ghana 
29. Dr Bernard Mbwele, MSc Clin.Research, Head of Clinical Operations, HIV/AIDS Care and Treatment \& PMTCT, Christian Social Service Commission, Mwanza, Tanzania

30. Dr HD Sama, Maître assistant en anesthésie reanimation, Anaesthesia Intensive Care Medicine Pain Management, Sylvanus Olympio University Teaching Hospital, 08 BP 8146 Tokoin, Lomé TOGO, Togo

31. Dr MA Elfiky, MD, Department of Surgery, Cairo University, Egypt

32. Prof M Fawzy, MD, Professor† and Head of Anesthesia, ICU \& Pain Management Departments, Faculty of Medicine, Cairo University, Egypt

33. Prof RM Pearse MD(Res), Professor $\dagger$ of Intensive Care Medicine, Queen Mary University of London, United Kingdom, EC1M 6BQ

$†$ Full professors

\section{Corresponding author}

Professor Bruce Biccard

Department of Anaesthesia and Perioperative Medicine,

Groote Schuur Hospital and University of Cape Town,

South Africa.

E-mail: bruce.biccard@uct.ac.za

Telephone: +27 (0) 761606387

Facsimile: +27 (0) 214066589 


\section{Research in context}

\section{Evidence before this study}

Safe, accessible and affordable surgery is a global health priority. It is estimated that 5 billion people do not have access to safe and affordable surgery, whilst an additional 143 million surgeries each year are needed in low and middleincome countries (LMICs) to address this need. However, there are limited surgical outcomes data from LMICs, and particularly few data from Africa. Two recent observational cohort studies only included a small number of African countries, with a limited range of surgeries reported. Increasing access to surgery is a priority in Africa, however it is essential to ensure that the surgery is safe, and that unnecessary perioperative morbidity and mortality is prevented. Because of the limited data of surgical outcomes data in Africa, there is an urgent need for a robust epidemiological study of perioperative patient outcomes to inform the global surgery initiative.

\section{Added value of this study}

The African Surgical Outcomes Study provides data from 25 African countries for all in-patient surgeries. One in five surgical patients in Africa develops a perioperative complication, following which, one in ten patients will die. Our findings show that, despite being younger with a low risk profile, and lower complication rates, patients in Africa are twice as likely to die following surgery when compared with outcomes at a global level. African surgical hospitals are under-resourced with a median combined total of specialist surgeons, obstetricians and anaesthesiologists of 0.7 ([25 $5^{\text {th }} / 75^{\text {th }}$ centile] $0.2-1.9$ ) per 100,000 population, far below the recommended number identified by the Lancet Commission on Global Surgery. The volume of surgical procedures is also very low at 212 (65-578) procedures per 100,000 population each year. Most surgical procedures are performed on an urgent or emergency basis, and one third are Caesarean deliveries. Importantly, 95\% of deaths occur after surgery, indicating the need to improve the safety of perioperative care.

\section{Implications of all the available evidence}

Previous studies have provided only limited data on surgical outcomes in Africa, through limited country participation and inclusion of selected surgical procedures. The African Surgical Outcomes Study provides a detailed insight into this problem. Our findings suggest a high incidence of potentially avoidable deaths amongst low-risk surgical patients, largely due to a failure to identify and treat life-threatening complications in the perioperative period. Limited availability of human and hospital resources may be a key factor. Despite the positive impact of the global safe surgery campaign, our findings show that surgical outcomes will remain poor in Africa, until the perioperative care of patients with deteriorating physiological function is addressed, and sufficient resources are available to provide this care. A 
continent-wide quality improvement strategy to promote effective perioperative care may save many lives after surgery in Africa. 


\section{Abstract}

\section{Background}

There is a need to increase access to surgical treatments in African countries, but perioperative complications represent a major global healthcare burden. There are few data describing surgical outcomes in Africa.

\section{Methods}

Seven-day, international, prospective, observational cohort study of patients $\geq 18$ years undergoing in-patient surgery in Africa. The primary outcome was in-hospital postoperative complications. The secondary outcome was in-hospital mortality. Data are presented as median $\left(25^{\text {th }} / 75^{\text {th }}\right.$ centile) and $n(\%)$.

\section{Findings}

11422 patients were recruited from 247 hospitals during the national cohort weeks between February and May 2016 in 25 African countries. Hospitals served a median population of 810,000 (200,000 - 2,000,000) people, with a combined number of specialist surgeons, obstetricians and anaesthetists totalling 0.7 (0.2-1.9) per 100,000 population. Hospitals recruited 29 (10-70) patients, equivalent to 212 (65-578) surgical procedures per 100,000 population each year. Patients were younger (38.5 [16 1] years), with a lower risk profile (American Society of Anesthesiologists score 1 [1-2]) than reported in high income countries. $1253(11 \cdot 0 \%)$ patients were infected with human immunodeficiency virus. 6504 procedures (57\%) were urgent or emergent. The most common procedure was Caesarean delivery (3792 patients, 33\%). Complications occurred in 1977/10885 (18·2\%) patients but overall mortality was more than twice the global average (239/11193 [2·1\%]), with 225/239 (94·1\%) deaths occurring after the day of surgery. Infection was the commonest complication (1156/10970, 10·2\%) with 112 deaths (9·7\%). Complications were associated with prolonged hospital stay (3 [2-5] days vs 6 [4-13] days; $\mathrm{p}<0 \cdot 001)$.

\section{Interpretation}

Despite a low risk profile and low complication rates, patients in Africa are twice as likely to die after surgery when compared to the global average. Initiatives to increase access to surgical treatments in Africa, must be coupled with improved surveillance for deteriorating physiology amongst patients who develop postoperative complications and the resources necessary to achieve this objective.

\section{Funding}

Medical Research Council of South Africa. 


\section{Introduction}

The surgical population represents a major global health burden with more than 300 million surgical procedures performed annually, ${ }^{1}$ and an early postoperative mortality of up to $4 \%{ }^{2,3}$ However, it has been estimated that 5 billion people are unable to access safe surgical treatments, ${ }^{4} 94 \%$ of whom live in low and middle-income countries (LMICs). ${ }^{4}$ Estimates suggest that globally, an additional 143 million surgical procedures are required each year, many of which are in Africa. ${ }^{4}$ Surgery is a cost-effective and core component of universal health coverage, ${ }^{5,67}$ but it needs to be safe. ${ }^{4}$ Known barriers to the provision of safe surgical treatment in Africa include low hospital procedural volumes, ${ }^{8}$ low numbers of hospital beds, ${ }^{9}$ and a paucity of operating theatres, ${ }^{10}$ all of which are compounded by the geographical remoteness of many surgical hospitals and a lack of adequately trained staff. ${ }^{11,12}$ The Lancet Commission on Global Surgery was established to develop strategies for safe, accessible and affordable surgical care, but implementation of this strategy requires robust epidemiological data describing patterns of surgical activity and subsequent patient outcomes. $^{7,13}$

Data describing surgical outcomes in Africa are particularly limited, and the findings of international studies are dominated by activity in high-income countries, with little participation from African countries. ${ }^{9,14}$ Furthermore, few African countries have national registries or audit systems to monitor surgical procedures and subsequent outcomes. Low Human Development Index (HDI) countries, many of which are African, are believed to have significantly higher perioperative mortality but this remains unconfirmed. ${ }^{14,15}$ The effect of population disease burden on the pattern of surgical outcomes in Africa is also unknown. Compared to high income countries, there is a preponderance of communicable diseases and injuries, ${ }^{14,16-18}$ of which human immunodeficiency virus (HIV) is the leading cause of life years lost in Africa. ${ }^{18}$

To improve both the provision and quality of surgical treatments in Africa, we need a detailed understanding of the volume of surgical treatments currently performed, the surgical resources available, and the associated patient outcomes. ${ }^{4}$ The objective of the African Surgical Outcomes Study (ASOS) was to provide robust epidemiological data describing the volume of surgical activity, perioperative outcomes, and surgical workforce density in Africa, which are comparable to published international surgical outcomes data. ${ }^{9}$ 


\section{Methods}

\section{Study design}

This was a seven day, international multicentre prospective observational cohort study of patients $\geq 18$ years undergoing any form of in-patient surgery in hospitals in African countries. This study was registered on the South African National Health Research Database (KZ_2015RP7_22), and on ClinicalTrials.gov (NCT03044899). Our findings are reported in accordance with the STROBE statement. ${ }^{19}$ A collaborative network of over 1000 healthcare professionals was established across Africa, through personal invitations to colleagues, invitations to surgical and anaesthesia societies, a website (www.asos.org.za) and a twitter feed (@africansos). BMB made country visits where possible to meet with local study investigators. A website provided investigator support, in the form of a regularly updated 'frequently asked questions' webpage, the protocol, case report forms (CRFs), and an outcomes definitions document in English and French (www.asos.org.za) $)$.

\section{Setting and participants}

In each country, we aimed to recruit as many hospitals as possible using a convenience sampling strategy. For inclusion of country data in the study we required; i) data from at least 10 hospitals or at least half of the surgical centres, if fewer than 10 in the country, ii) submission of the total number of eligible patients during recruitment week, and iii) provision of data describing at least $90 \%$ of the eligible patients from each site. Each country selected a single recruitment week between February and May 2016. All patients undergoing elective and non-elective surgery with a planned overnight hospital stay following surgery during the study week were eligible for inclusion. Patients undergoing planned day surgery, or radiological procedures not requiring anaesthesia were excluded. Regulatory approval varied between countries, with some requiring ethics approval and others only data governance approval. The primary ethics approval was from the Biomedical Research Ethics Committee of the University of KwaZulu-Natal, South Africa (BE306/15). All sites approved a waiver of consent, except the University of the Witwatersrand, South Africa which required informed consent from all patients, with deferred consent for patients who could not give consent prior to surgery.

\section{Variables and data}

Hospital-specific data included the number of hospital beds, number of operating rooms, number of critical care beds, and numbers of anaesthetists, surgeons and obstetricians working in each hospital. We replicated the design of a recent global study, with an almost identical patient dataset to allow a direct comparison of surgical outcomes data from Africa with surgical outcomes at a global level.${ }^{9,20}$ Complications were assessed according to predefined criteria and graded as mild, moderate or severe. ${ }^{20}$ Data describing consecutive patients were collected on paper case record forms until hospital discharge, censored at 30 days following surgery for patients who remained in hospital. Data were anonymised 
during the transcription process using REDCap (Research Electronic Data Capture) tools hosted by Safe Surgery South Africa. REDCap is a secure, web-based application designed to support data capture for research studies. ${ }^{21}$ Soft limits were set for data entry, prompting investigators when data were entered outside these limits. In countries with poor internet access, mobile phones were used for data entry, or CRFs were forwarded to BMB, for entry by Safe Surgery South Africa. National leaders confirmed the face validity of the unadjusted outcome data for their countries, and hospital level data were evaluated statistically to confirm plausibility.

\section{Outcome measures}

The primary outcome measure was in-hospital postoperative complications defined according to the consensus definitions by Jammer et al. ${ }^{20}$ The secondary outcome measure was in-hospital mortality. All outcomes were censored at 30 days for patients who remained in hospital. Outcomes data are presented at a national, regional (central, eastern, northern, southern, western African, and Indian Ocean Islands) and continental level. The outcomes definitions document is in the Supplementary Appendix.

\section{Statistical analysis}

There was no prespecified sample size, as the aim was to recruit as many hospitals as possible, and ideally every eligible patient from recruiting hospitals. We anticipated that a minimum sample size of 10,000 patients would provide a sufficient number of events for construction of a robust continental logistic regression model. ${ }^{22}$ Although this study can provide an estimate of continental mortality, it was not powered to detect differences in mortality between countries. During the process of hospital recruitment and data collection, we realised that our predefined criteria for including a national patient sample were too strict for many countries, despite formal acceptance by the national leaders of these requirements before the study began. Prior to analysis, we took the decision to present the data describing the full cohort, and include a per-protocol analysis of the predefined representative sample for comparison.

Categorical variables are described as proportions and compared using Fisher's exact test. Continuous variables are described as mean and standard deviation, or median and $25^{\text {th }} / 75^{\text {th }}$ centile, and compared using t-tests. For country specific mortality comparison, we constructed a multivariable logistic model that included all potential risk factors associated with in-hospital mortality. These included; age, smoker status, gender, American Society of Anesthesiologists (ASA) category, preoperative chronic comorbid conditions (coronary artery disease, congestive heart failure, diabetes mellitus, cirrhosis, metastatic cancer, hypertension, stroke, chronic obstructive pulmonary disease, HIV, chronic renal disease), the type of surgery, urgency of surgery (elective, urgent or emergency) and the severity of surgery (minor, intermediate or major). To avoid collinearity of potential risk factors, variables with variance inflation factor $>2$ were excluded. For all analyses, we performed a complete case analysis, excluding patients with missing data 
from the analysis. South Africa, the country with the largest number of observed events was used as the reference country. Orthopaedic surgery as the largest noncardiac, non-obstetric surgical category was used as surgical reference category. Restricted cubic splines were used to fit continuous variables. ${ }^{23}$ Model performances were evaluated by assessing the calibration and discrimination of the model. A smooth, nonparametric calibration line was created with the LOESS algorithm (i.e. a locally weighted scatterplot smoothing) to estimate the observed probabilities of in-hospital mortality in relation to the predicted probabilities. Discrimination was quantified by calculating the concordance statistic (c-statistic) completed with optimism, ${ }^{24}$ which relates to both model coefficients estimation and over-fitting (e.g. selection of predictors, categorization of continuous predictors). We conducted four sensitivity analyses of the association between preoperative risk factors and mortality. These included; i) a per-protocol sensitivity analysis of only the patients from the hospitals which provided hospital facility data, ii) a full case sensitivity analysis, with multiple imputation of missing data to test for potential bias associated with missing variables, ${ }^{25}$ and iii) two further analyses which explored the effect of the hospital facility level or university-affiliation on mortality. In these two analyses, we either forced hospital facility level or university-affiliation into the model. Statistical analyses were performed using the Statistical Package for the Social Sciences (SPSS) version 24 (SPSS Inc., Chicago, IL, USA) and R statistical software package version 3.4 (R Foundation for Statistical Computing, Austria).

\section{Role of funding source}

The study was funded by an investigator initiated research grant from the Medical Research Council of South Africa awarded to BMB. The study website (www.asos.org.za) and the data repository was maintained by Safe Surgery South Africa and the South African Society of Anaesthesiologists. These organisations played no role in the study design, data acquisition, data analysis or writing of the paper.

BMB, YLM and TME had full access to the data. BMB and RMP had responsibility for submission of the manuscript. 


\section{Results}

\section{Country and hospital data}

247 hospitals participated in 25 African countries (Figures 1 and 2). These included 14 low-income countries (Benin, Burundi, Congo, Democratic Republic of the Congo (DRC), Ethiopia, Gambia, Madagascar, Mali, Niger, Senegal, Tanzania, Togo, Uganda, and Zimbabwe) and 11 middle-income countries (Algeria, Cameroon, Egypt, Ghana, Kenya, Libya, Mauritius, Namibia, Nigeria, South Africa, and Zambia). Hospital level data were submitted for 216 of 247 (87·4\%) participating hospitals. 173/216 (80·1\%) were government-funded hospitals, 28/216 (12·0\%) privately funded, and 15/216 (6.9\%) jointly funded hospitals. 103/212 (48·6\%) were university-affiliated hospitals. 45/216 (20·8\%) were primary-level hospitals (defined as mainly obstetrics and gynaecology and general surgery), 68/216 (31·4\%) were secondary-level hospitals (defined as highly differentiated by function with 5 to 10 clinical specialities), and 103/216 (47-7\%) were tertiary-level (defined as specialised staff or technical support) hospitals. ${ }^{26}$ Each hospital served a median population of 880000 (200000-2000000) people, with 300 (140-545) beds, 6 (2-7) operating rooms and 3 (0-7) critical care beds providing invasive ventilation. The ratio of critical care beds to hospital beds was $0 \cdot 9 \%(0-2 \cdot 0)$. Hospitals were staffed by 3 (1-8) specialist surgeons, 1 (0-5) specialist anaesthetists, and $2(0-5)$ specialist obstetricians, with a median of $0 \cdot 7(0 \cdot 2-1 \cdot 9)$ of any specialist per 100,000 population. The median number of surgical procedures per hospital for the study week was 29 (10-71).

\section{Patient data}

11422 patients were recruited (Figure 2). The patient characteristics, perioperative complications and mortality are shown in Table 1. Most patients had a low perioperative risk profile. They were young (38.5 years [16·1]), with an American Society of Anesthesiologists (ASA) physical status score of 1 [1-2]). The most common comorbidities were hypertension (1863 patients, 16•3\%) and HIV (1253 patients, 11·0\%). Most surgery was urgent or emergent (6504/11378, 57\%). The most common procedure was Caesarean delivery (3792/11393, 33·3\%). The World Health Organisation Safe Surgery Checklist or a similar surgical checklist was used in 6183/10836 (57·1\%) of surgeries.

Patient outcomes following surgery are shown in Table 2. There were 239 deaths after surgery (2·1\%), only 14 (5·9\%) of which occurred on the day of surgery. The median time of death was 5 [2-11] days postoperatively. Postoperative complications occurred in 1977/10885 (18·2\% [95\% CI 17·4-18·9]), with a mortality of 188/1970 (9·5\% [95\% 8·210·8\%]). 321/1972 (16 3\%) patients with postoperative complications were admitted to critical care to treat these complications, of whom 255/321 (79·4\%) were admitted to critical care immediately after surgery. Complications were associated with prolonged hospital stay (3 [2-5] days vs 6 [4-13] days; $p<0 \cdot 001$ ). Individual postoperative complications are shown in Table 3. Infectious complications were most common whilst cardiovascular complications 
were associated with the highest mortality (110/190, 57·9\%). Cardiac arrest was associated with a 101/113 (89·4\%) inhospital mortality. The proportional contribution of non-communicable diseases, infection, trauma and caesarean delivery as the primary indication for surgery to mortality and postoperative complications is shown in Table 4 . Noncommunicable diseases were the most common indication for surgery, however significantly more postoperative complications and death followed surgery for infection and trauma.

The country specific data are shown in Supplementary Table 1. The model to describe mortality had poor discrimination for mortality (c-statistic corrected for optimism of $0 \cdot 53$, Brier of $0 \cdot 0222$ for mortality) when based on the countries alone. However, the adjusted model for country specific mortality showed good discrimination for mortality (c-statistic corrected for optimism of 0·83, Brier of 0 0222) (Supplementary Table 2). The calibration plot for inhospital mortality is shown in Supplementary Figure 1. After risk-adjustment, most countries had a similar risk of mortality. Postoperative mortality was strongly associated with increasing ASA grade, urgency of surgery, and grade of surgery (intermediate and major). Gastrointestinal, hepatobiliary and neurosurgery were associated with increased mortality.

When compared to a recent global epidemiological study of elective surgery (International Surgical Outcomes Study, or ISOS), ${ }^{9}$ the elective surgical patients in the ASOS cohort were younger, had a lower risk profile, and underwent more minor surgery. Patients in ASOS experienced fewer postoperative complications (Supplementary Table 3). The comparison between the postoperative mortality, postoperative complications, and mortality following postoperative complications, after elective surgery in the ISOS high-income and LMICs, and the African countries of the ASOS cohort, is shown in Figure 3 and Supplementary Figure 2. Mortality amongst surgical patients in Africa was twice the global average represented by the ISOS cohort.

The per-protocol analysis of the hospital data, patient data, patient outcomes, postoperative complications and the primary indication for surgery are shown in Supplementary Tables 4-8. The regional country participation is shown in Supplementary Figure 3, and the African regional outcomes are shown in Supplementary Table 9.

\section{Sensitivity analyses}

The outcomes reported according to hospital facility level are shown in Supplementary Table 10. The per-protocol sensitivity analysis of only the patients from the hospitals which provided complete hospital facility data are shown in Supplementary Table 11. The full case sensitivity analysis, with multiple imputation of missing data to test for potential bias associated with missing variables is shown in Supplementary Table 12. Both these sensitivity analyses provided similar results to the primary multivariable analysis. The sensitivity analyses which explored the effect of the hospital 
facility level or university-affiliation on mortality are shown in Supplementary Tables 13 and 14. Hospitals of a higher facility level were independently associated with increased mortality, but university-affiliation was not. None of the sensitivity analyses have altered our overall findings. 


\section{Discussion}

\section{Key findings}

The principal finding of this study was that surgical patients in Africa are younger, with a low risk profile and low complication rates, and yet are twice as likely to die when compared to the global average. Approximately one in five surgical patients in Africa develops a postoperative complication, and one in ten of these patients will die. It is likely that many of these deaths are preventable. This large prospective cohort of surgery in 247 hospitals in 25 African countries, has revealed the limited workforce resources to provide safe surgical treatment. While it is imperative to increase access to surgery for the people of Africa, it is essential that that these surgical treatments are safe and effective. ${ }^{27}$ Importantly, 95\% of deaths occur in the postoperative period, suggesting that many lives could be saved by effective surveillance for physiological deterioration amongst patients who have developed complications and addressing the resources necessary to achieve this objective. Surgical outcomes will remain poor in Africa ${ }^{15}$ until this problem is addressed.

\section{Interpretation}

Our results indicate that postoperative mortality following surgery is significantly higher in Africa, when compared to other international cohorts, despite a lower patient risk profile and lower postoperative complication rates. ${ }^{9}$ Improving the quality of surgery is a function of structures, processes and outcomes as defined by the Lancet Commission on Global Surgery. ${ }^{4}$ Our results provide important data on some of the processes and outcomes which need to be addressed in Africa. The great majority of these deaths occur on the days following surgery, and it seems likely that many are preventable. There are few published reports of postoperative outcomes in Africa, but our interpretation is consistent with the findings of a number of smaller epidemiological studies exploring postoperative mortality in African countries, with described mortality rates which were similar to, ${ }^{14,28}$ or higher than those in the current study. ${ }^{29,30}$ In a recent global study of mortality following emergency abdominal surgery, the majority of deaths also occurred more than 24 hours surgery. ${ }^{14}$ Our observations are also consistent with reports of intraoperative and/or anaesthetic related mortality rates in low-income countries. ${ }^{15,31}$ The findings of the current and previous work may be partly explained by the limited workforce resources, and poor early warning systems to detect the physiological deterioration of the patients who have developed complications. ${ }^{32}$ The median number of $0 \cdot 7$ specialists (a combined total of surgeons, obstetricians and anaesthesiologists) per 100,000 population in this study, is well below the inflection point of 20 to 40 specialists per 100,000 thought necessary to decrease perioperative mortality. ${ }^{4}$ Furthermore, there are fewer hospital, and critical care bed resources than recently reported at the global level. ${ }^{9}$ Consequently, mortality following perioperative complications is significantly greater in Africa. The problem of unrecognised postoperative physiological deterioration on the surgical ward has been well described. ${ }^{32}$ Interventions such as early warning scores, critical care outreach, medical emergency 
teams, and critical care skills training for junior surgeons, are now standard in most high-income countries. 'Failure to rescue' and similar metrics have been successfully used to support data driven quality improvement projects. ${ }^{33}$ Our findings suggest that the drivers of perioperative death may be broadly consistent across Africa, although further prospective audit is required to understand the site-specific drivers in individual hospitals, and countries. Recent work has demonstrated the feasibility of surgical outcomes audit in low-income countries. ${ }^{28,34}$ A pragmatic continent-wide quality improvement programme may improve the allocation of resources towards the postoperative surveillance of patients most at risk. A simple surgical risk calculator may facilitate this approach.

\section{Strengths and limitations}

To our knowledge, this is the most comprehensive evaluation of surgical workforce density and patient outcomes following surgery conducted so far in Africa. Although, our study was not designed to inform detailed healthcare policy decisions in individual countries, the data are likely to have a significant impact throughout Africa. It seems likely that the drivers of morbidity and mortality are similar across these countries. Some of the country level data presented may provide the outcomes information required to power future country-specific studies of postoperative morbidity and mortality. Assuming a mortality rate of $2 \%$ and a $18 \%$ postoperative complication rate, an individual country-level surgical outcomes audit would require a 3000 patient sample to provide a reliable mortality estimate with a $95 \%$ confidence interval of $1 \%$, and a 1400 patient sample to provide reliable complication rate with a 95\% confidence interval of $4 \%$. We used a simple data set consisting primarily of categorical variables to minimise the amount of missing data. Patient-level variables were selected on the basis that they were objective, routinely collected for clinical reasons, could be accurately transcribed with a low rate of missing data, and would be relevant to a risk adjustment model which included a variety of surgical procedures. National co-ordinators confirmed the face validity of their raw data prior to analysis.

The study also has some weaknesses. The 7-day cohort design was chosen as a pragmatic approach to tackling the paucity of epidemiological data describing this population. However, care should be taken in applying our findings in individual hospitals and countries. Variation in factors such as seasonal weather, industrial action, available healthcare workforce, armed conflict, surgical workload, and the healthcare seeking behaviour of patients, may all influence our results. Furthermore, these factors may also affect direct comparisons of surgical outcomes with high income countries. Fourteen countries did not provide per-protocol data samples, which may compromise the generalizability to these countries. However, it is possible that those hospitals unable to meet our protocol requirements face even greater difficulties in ensuring good patient outcomes. Indeed, more than half the countries in our study could not fulfil the protocol requirements for an included sample, and in hindsight these rules were inappropriately strict. Whilst 25 African countries participated, this was fewer than half of the countries in Africa, and a number of low-income countries did not 
take part. Generalization to those unrepresented countries must be cautious, although it is possible that they too may have particular difficulties in delivering good surgical outcomes. Nearly half of the hospitals included in this study were university affiliated, and it is possible that our findings may underestimate poor patient outcomes reflected in smaller, more remote hospitals. We defined complications according to published criteria, also used in the ISOS study. ${ }^{9}$ These definitions were developed in high-income countries, and it is possible that some complications were under-reported due to limited access to diagnostic tests, for example in the case of myocardial infarction. Meanwhile the assessment of some other complications can be subjective, in particular surgical site infection. Whilst few of our investigators were experienced researchers, it was beyond of the scope of this project to train them in a standard approach to assessing individual complications. This may have resulted in variability between hospitals. It is important to note that our primary focus was on all complications, rather than a specific individual complication. We carefully replicated the design of the previous ISOS study to allow comparison with the current global standard, but it should be noted that this comparison was not fully contemporaneous as these data were collected in 2014 whilst ASOS was conducted in 2016.

\section{Conclusions}

Surgical patients in Africa are younger, with a lower risk profile and low complication rates, but twice as likely to die when compared to the global average. Most deaths occur after surgery suggesting a need to improve the safety through postoperative surveillance for deteriorating patients on the ward. Contributory factors include limited numbers of specialists, poor hospital infrastructure, and low procedural volumes. The Lancet Commission on Global Surgery advocates improving access to safe, accessible and affordable surgical care. This study highlights the importance of effective perioperative care to achieving this objective in Africa. A pragmatic continent-wide quality improvement programme, including prospective audit, may reduce the number of preventable deaths following surgery in Africa. 


\section{Contributors}

All authors were involved in the design and conduct of the study. Data collection and collation was done by the ASOS local investigators. The data analysis was conducted by BMB, TME and YLM. The first draft of the paper was written by BMB. The paper was redrafted by BMB following critical review by all authors.

\section{Conflicts of interest}

RP has received research grants from Edwards Lifesciences, Nestle Health Sciences and Intersurgical, has given lectures and/or performed consultancy work for Nestle Health Sciences, Medtronic, Edwards Lifesciences, BBraun and Glaxo Smithkline, and is a member of the associate editorial board of the British Journal of Anaesthesia. The authors declare that they have no conflict of interest.

\section{Funding}

The study was funded by a self-initiated Medical Research Council of South Africa grant awarded to BMB. The study website was maintained by the Safe Surgery South Africa (SSSA). They had no role in the study design, data acquisition, data analysis or writing up of the paper. 


\section{References}

1. Weiser TG, Haynes AB, Molina G, et al. Estimate of the global volume of surgery in 2012: an assessment supporting improved health outcomes. Lancet 2015; 385 Suppl 2: S11.

2. Devereaux PJ, Chan MT, Alonso-Coello P, et al. Association between postoperative troponin levels and 30-day mortality among patients undergoing noncardiac surgery. Jama 2012; 307(21): 2295-304.

3. Pearse RM, Moreno RP, Bauer P, et al. Mortality after surgery in Europe: a 7 day cohort study. Lancet 2012; 380(9847): 1059-65.

4. $\quad$ Meara JG, Leather AJ, Hagander L, et al. Global Surgery 2030: evidence and solutions for achieving health, welfare, and economic development. Lancet 2015; 386(9993): 569-624.

5. Chao TE, Sharma K, Mandigo M, et al. Cost-effectiveness of surgery and its policy implications for global health: a systematic review and analysis. Lancet Glob Health 2014; 2(6): e334-45.

6. Grimes CE, Henry JA, Maraka J, Mkandawire NC, Cotton M. Cost-effectiveness of surgery in low- and middle-income countries: a systematic review. World J Surg 2014; 38(1): 252-63.

7. Dare AJ, Grimes CE, Gillies R, et al. Global surgery: defining an emerging global health field. Lancet 2014; 384(9961): 2245-7.

8. $\quad$ Rose J, Weiser TG, Hider P, Wilson L, Gruen RL, Bickler SW. Estimated need for surgery worldwide based on prevalence of diseases: a modelling strategy for the WHO Global Health Estimate. Lancet Glob Health 2015; 3 Suppl 2: S13-20.

9. Global patient outcomes after elective surgery: prospective cohort study in 27 low-, middleand high-income countries. Br J Anaesth 2016; 117(5): 601-9.

10. Funk LM, Weiser TG, Berry WR, et al. Global operating theatre distribution and pulse oximetry supply: an estimation from reported data. Lancet 2010; 376(9746): 1055-61.

11. Aiken LH, Clarke SP, Cheung RB, Sloane DM, Silber JH. Educational levels of hospital nurses and surgical patient mortality. Jama 2003; 290(12): 1617-23.

12. Griffiths P, Jones S, Bottle A. Is "failure to rescue" derived from administrative data in England a nurse sensitive patient safety indicator for surgical care? Observational study. Int J Nurs Stud 2013; 50(2): 292-300.

13. Meara JG, Hagander L, Leather AJ. Surgery and global health: a Lancet Commission. Lancet 2014; 383(9911): 12-3.

14. GlobalSurg C. Mortality of emergency abdominal surgery in high-, middle- and low-income countries. Br J Surg 2016; 103(8): 971-88.

15. Bainbridge D, Martin J, Arango M, Cheng D, Evidence-based Peri-operative Clinical Outcomes Research G. Perioperative and anaesthetic-related mortality in developed and developing countries: a systematic review and meta-analysis. Lancet 2012; 380(9847): 1075-81.

16. Murray CJ, Vos T, Lozano R, et al. Disability-adjusted life years (DALYs) for 291 diseases and injuries in 21 regions, 1990-2010: a systematic analysis for the Global Burden of Disease Study 2010. Lancet 2012; 380(9859): 2197-223.

17. Biccard BM, Madiba TE, South African Surgical Outcomes Study I. The South African Surgical Outcomes Study: A 7-day prospective observational cohort study. S Afr Med J 2015; 105(6): 465-75.

18. Lozano R, Naghavi M, Foreman K, et al. Global and regional mortality from 235 causes of death for 20 age groups in 1990 and 2010: a systematic analysis for the Global Burden of Disease Study 2010. Lancet 2012; 380(9859): 2095-128.

19. von Elm E, Altman DG, Egger M, Pocock SJ, Gotzsche PC, Vandenbroucke JP. The Strengthening the Reporting of Observational Studies in Epidemiology (STROBE) statement: guidelines for reporting observational studies. PLoS Med 2007; 4(10): e296.

20. Jammer I, Wickboldt N, Sander M, et al. Standards for definitions and use of outcome measures for clinical effectiveness research in perioperative medicine: European Perioperative Clinical Outcome (EPCO) definitions: a statement from the ESA-ESICM joint taskforce on perioperative outcome measures. Eur J Anaesthesiol 2015; 32(2): 88-105.

21. Harris PA, Taylor R, Thielke R, Payne J, Gonzalez N, Conde JG. Research electronic data capture (REDCap)--a metadata-driven methodology and workflow process for providing translational research informatics support. J Biomed Inform 2009; 42(2): 377-81.

22. Peduzzi P, Concato J, Kemper E, Holford TR, Feinstein AR. A simulation study of the number of events per variable in logistic regression analysis. J Clin Epidemiol 1996; 49(12): 13739.

23. Harrell FE. Regression Modeling Strategies: With Applications to Linear Models, Logistic Regression, and Survival Analysis: Springer, New York; 2001. 
24. Austin PC, Steyerberg EW. Interpreting the concordance statistic of a logistic regression model: relation to the variance and odds ratio of a continuous explanatory variable. BMC Med Res Methodol 2012; 12: 82.

25. Sterne JA, White IR, Carlin JB, et al. Multiple imputation for missing data in epidemiological and clinical research: potential and pitfalls. Bmj 2009; 338: b2393.

26. Jamison DT, Breman JG, Measham AR, et al. Disease Control Priorities in Developing Countries. Washington: Oxford University Press; 2006.

27. Flott K, Fontana G, Dhingra-Kumar N, Yu A, Durkin M, Darzi A. Health care must mean safe care: enshrining patient safety in global health. Lancet 2017; 389(10076): 1279-81.

28. Sileshi B, Newton MW, Kiptanui J, et al. Monitoring Anesthesia Care Delivery and Perioperative Mortality in Kenya Utilizing a Provider-driven Novel Data Collection Tool. Anesthesiology 2017; 127(2): 250-71.

29. Rickard JL, Ntakiyiruta G, Chu KM. Associations with Perioperative Mortality Rate at a Major Referral Hospital in Rwanda. World J Surg 2016; 40(4): 784-90.

30. Davies JF, Lenglet A, van Wijhe M, Ariti C. Perioperative mortality: Analysis of 3 years of operative data across 7 general surgical projects of Medecins Sans Frontieres in Democratic Republic of Congo, Central African Republic, and South Sudan. Surgery 2016; 159(5): 1269-78.

31. Chu KM, Ford N, Trelles M. Operative mortality in resource-limited settings: the experience of Medecins Sans Frontieres in 13 countries. Arch Surg 2010; 145(8): 721-5.

32. McGinley A, Pearse RM. A national early warning score for acutely ill patients. Bmj 2012; 345: e5310.

33. Ahmad T, Bouwman RA, Grigoras I, et al. Use of failure to rescue to identify international variation in postoperative care in low, middle and high income countries: Analysis of data from a seven day cohort study of elective surgery. British Journal of Anaesthesia 2017; 119(2): 258-66.

34. Grimes CE, Billingsley ML, Dare AJ, et al. The demographics of patients affected by surgical disease in district hospitals in two sub-Saharan African countries: a retrospective descriptive analysis. Springerplus 2015; 4: 750. 
Necessary additional data
Click here to download Nec

Click here to download Necessary additional data: 2. ASOS Investigator List Lancet submission.docx

x


Table 1 Description of the African Surgical Outcomes Study (ASOS) patient cohort.

\begin{tabular}{|c|c|c|c|c|c|}
\hline & $\begin{array}{c}\text { All patients } \\
(n=11422)\end{array}$ & $\begin{array}{c}\text { Patients with complications } \\
(\mathrm{n}=1977)\end{array}$ & $\begin{array}{l}\text { Patients with no complications } \\
(\mathrm{n}=\mathbf{8 9 0 8 )}\end{array}$ & $\begin{array}{c}\text { Patients who died } \\
(\mathrm{n}=239)\end{array}$ & $\begin{array}{c}\text { Patients who survived } \\
(\mathrm{n}=10954)\end{array}$ \\
\hline Age (years) & $\begin{array}{c}38 \cdot 5(16 \cdot 1) \\
34 \cdot 0(24 \cdot 0-48 \cdot 0)\end{array}$ & $\begin{array}{c}40 \cdot 7(17 \cdot 5) \\
36 \cdot 0(27 \cdot 0-53 \cdot 0)\end{array}$ & $\begin{array}{c}38 \cdot 0(15 \cdot 8) \\
33 \cdot 0(26 \cdot 0-47 \cdot 0)\end{array}$ & $\begin{array}{c}49 \cdot 5(19 \cdot 1) \\
51 \cdot 0(32 \cdot 0-64 \cdot 0)\end{array}$ & $\begin{array}{c}38 \cdot 3(16 \cdot 0) \\
34 \cdot 0(26 \cdot 0-47 \cdot 0)\end{array}$ \\
\hline Male & $3833 / 11418(33 \cdot 6 \%)$ & $819 / 1977(41 \cdot 4 \%)$ & $2832 / 8908(31 \cdot 8 \%)$ & $121 / 239(50 \cdot 6 \%)$ & $3656 / 10953(33 \cdot 4 \%)$ \\
\hline Current smoker & $1520 / 11367(16 \cdot 8 \%)$ & $315 / 1972(16 \cdot 0 \%)$ & $1351 / 8881(15 \cdot 2 \%)$ & $38 / 235(16 \cdot 2 \%)$ & $1688 / 10924(15 \cdot 5 \%)$ \\
\hline \multicolumn{6}{|l|}{ ASA category } \\
\hline 1 & $5713 / 11352(50 \cdot 3 \%)$ & 781/1962 (39·8\%) & $4675 / 8887(52 \cdot 6 \%)$ & $45239(18 \cdot 8 \%)$ & $5552 / 10899(50 \cdot 9 \%)$ \\
\hline 2 & $4199 / 11352(37 \cdot 0 \%)$ & 705/1962 (35.9\%) & $3309 / 8887(37 \cdot 2 \%)$ & $62 / 239(25 \cdot 9 \%)$ & $4050 / 10899(37 \cdot 2 \%)$ \\
\hline 3 & $1197 / 11352(10 \cdot 5 \%)$ & $354 / 1962(18 \cdot 0 \%)$ & $804 / 8887(9 \cdot 0 \%)$ & 79/239 (33·1\%) & $1111 / 10899(10 \cdot 2 \%)$ \\
\hline 4 & $234 / 11352(2 \cdot 1 \%)$ & $117 / 1962(6 \cdot 0 \%)$ & $96 / 8887(1 \cdot 1 \%)$ & $47 / 239(19 \cdot 7 \%)$ & $184 / 10899(1 \cdot 7 \%)$ \\
\hline 5 & $9 / 11352(0 \cdot 1 \%)$ & $5 / 1962(0 \cdot 3 \%)$ & $3 / 8887(0 \%)$ & $6 / 239(2 \cdot 5 \%)$ & $2 / 10899(0 \%)$ \\
\hline \multicolumn{6}{|l|}{ Grade of surgery } \\
\hline Minor & $2459 / 11341(21 \cdot 7 \%)$ & $277 / 1972(14 \cdot 0 \%)$ & $2064 / 8888(23 \cdot 2 \%)$ & $28 / 238(11 \cdot 8 \%)$ & $2392 / 10920(21 \cdot 9 \%)$ \\
\hline Intermediate & $5487 / 11341(48 \cdot 4 \%)$ & $852 / 1972(48 \cdot 5 \%)$ & $4415 / 8888(49 \cdot 7 \%)$ & $96 / 238(40 \cdot 3 \%)$ & $5322 / 10920(48 \cdot 7 \%)$ \\
\hline Major & $3395 / 11341(29 \cdot 7 \%)$ & $843 / 1972(42 \cdot 7 \%)$ & $2409 / 8888(27 \cdot 1 \%)$ & $114 / 238(47 \cdot 9 \%)$ & $3206 / 10920(29 \cdot 4 \%)$ \\
\hline \multicolumn{6}{|l|}{ Urgency of surgery } \\
\hline Elective & $4874 / 11378(42 \cdot 8 \%)$ & $624 / 1970(31 \cdot 7 \%)$ & $4034 / 8896(45 \cdot 3 \%)$ & $48 / 239(20 \cdot 1 \%)$ & $4744 / 10928(43 \cdot 4 \%)$ \\
\hline Urgent & $2700 / 11378(23 \cdot 7 \%)$ & $519 / 1970(26 \cdot 3 \%)$ & $2036 / 8896(22 \cdot 9 \%)$ & $77 / 239(32 \cdot 2 \%)$ & $2562 / 10928(23 \cdot 4 \%)$ \\
\hline Emergency & $3804 / 11378(33 \cdot 4 \%)$ & $827 / 1970(42 \cdot 0 \%)$ & $2826 / 8896(31 \cdot 8 \%)$ & $114 / 239(47 \cdot 7 \%)$ & $3622 / 10928(33 \cdot 1 \%)$ \\
\hline \multicolumn{6}{|l|}{ Surgical speciality } \\
\hline Orthopaedic & $1770 / 11393(15 \cdot 5 \%)$ & 292/1977 (14·8\%) & $1372 / 8902(15 \cdot 4 \%)$ & $27 / 239(11 \cdot 3 \%)$ & $1710 / 11179(15 \cdot 6 \%)$ \\
\hline Breast & $229 / 11393(2 \cdot 0 \%)$ & $31 / 1977(1 \cdot 6 \%)$ & $192 / 8902(2 \cdot 2 \%)$ & $2 / 239(0 \cdot 8 \%)$ & $227 / 11179(2 \cdot 1 \%)$ \\
\hline Obstetrics & $3792 / 11393(33 \cdot 3 \%)$ & $531 / 1977(26 \cdot 9 \%)$ & $3074 / 8902(34 \cdot 5 \%)$ & $20 / 239(8 \cdot 4 \%)$ & $3664 / 11179(33 \cdot 5 \%)$ \\
\hline Gynaecology & $1305 / 11393(11 \cdot 5 \%)$ & $153 / 1977(7 \cdot 7 \%)$ & $1102 / 8902(12 \cdot 4 \%)$ & $7 / 239(2 \cdot 9 \%)$ & $1285 / 11179(11 \cdot 7 \%)$ \\
\hline Upper GIT & $301 / 11393(2 \cdot 6 \%)$ & $102 / 1977(5 \cdot 2 \%)$ & $191 / 8902(2 \cdot 1 \%)$ & $29 / 239(12 \cdot 1 \%)$ & $268 / 11179(2 \cdot 4 \%)$ \\
\hline Lower GIT & $940 / 11393(8 \cdot 3 \%)$ & $228 / 1977(11 \cdot 5 \%)$ & $670 / 8902(7 \cdot 5 \%)$ & $46 / 239(19 \cdot 2 \%)$ & $872 / 11179(8 \cdot 0 \%)$ \\
\hline Hepatobiliary & $172 / 11393(1 \cdot 5 \%)$ & $28 / 1977(1 \cdot 4 \%)$ & $139 / 8902(1 \cdot 6 \%)$ & $4 / 239(1 \cdot 7 \%)$ & $168 / 11179(1 \cdot 5 \%)$ \\
\hline Urology and kidney & $560 / 11393(4 \cdot 9 \%)$ & $108 / 1977(5 \cdot 5 \%)$ & $430 / 8902(4 \cdot 8 \%)$ & $13 / 239(5 \cdot 4 \%)$ & $541 / 11179(4 \cdot 9 \%)$ \\
\hline Vascular & $237 / 11393(2 \cdot 1 \%)$ & $72 / 1977(3 \cdot 6 \%)$ & $153 / 8902(1 \cdot 7 \%)$ & $16 / 239(6 \cdot 7 \%)$ & $219 / 11179(2 \cdot 0 \%)$ \\
\hline Head and neck & $453 / 11393(4 \cdot 0 \%)$ & $68 / 1977(3 \cdot 4 \%)$ & $356 / 8902(4 \cdot 0 \%)$ & $13 / 239(5 \cdot 4 \%)$ & $431 / 11179(3 \cdot 9 \%)$ \\
\hline Cardiac surgery & $58 / 11393(0 \cdot 5 \%)$ & $21 / 1977(1 \cdot 1 \%)$ & $35 / 8902(0 \cdot 4 \%)$ & $6 / 239(2 \cdot 5 \%)$ & $52 / 11179(0 \cdot 5 \%)$ \\
\hline Thoracic (lung and other) & $130 / 11393(1 \cdot 1 \%)$ & $37 / 1977(1 \cdot 9 \%)$ & $92 / 8902(1 \cdot 0 \%)$ & $8 / 239(3 \cdot 3 \%)$ & $122 / 11179(1 \cdot 1 \%)$ \\
\hline Thoracic (gut) & $23 / 11393(0 \cdot 2 \%)$ & $9 / 1977(0 \cdot 5 \%)$ & $14 / 8902(0 \cdot 2 \%)$ & $2 / 239(0 \cdot 8 \%)$ & $21 / 11179(0 \cdot 2 \%)$ \\
\hline Neurosurgery & $253 / 11393(2 \cdot 2 \%)$ & $85 / 1977(4 \cdot 3 \%)$ & $156 / 8902(1 \cdot 8 \%)$ & $21 / 239(8 \cdot 8 \%)$ & $230 / 11179(2 \cdot 1 \%)$ \\
\hline Other & $555 / 11393(4 \cdot 9 \%)$ & 79/1977 (4.0\%) & $471 / 8902(5 \cdot 3 \%)$ & $11 / 239(4 \cdot 6 \%)$ & $541 / 11179(4 \cdot 9 \%)$ \\
\hline Surgical checklist & $6183 / 10836(57 \cdot 1 \%)$ & 1082/1971 (54.9\%) & $5101 / 8865(57 \cdot 5 \%)$ & $145 / 239(60 \cdot 7 \%)$ & $6188 / 10894(56 \cdot 8 \%)$ \\
\hline \multicolumn{6}{|l|}{ Comorbidity } \\
\hline Coronary artery disease & $178 / 11422(1 \cdot 6 \%)$ & $53 / 1977(2 \cdot 7 \%)$ & $119 / 8908(1 \cdot 3 \%)$ & $11 / 239(4 \cdot 6 \%)$ & $166 / 10954(1 \cdot 5 \%)$ \\
\hline Congestive heart failure & $92 / 11422(0 \cdot 8 \%)$ & $30 / 1977(1 \cdot 5 \%)$ & $58 / 8908(0 \cdot 7 \%)$ & $11 / 239(4 \cdot 6 \%)$ & $80 / 10954(0 \cdot 7 \%)$ \\
\hline Diabetes mellitus & $776 / 11422(6 \cdot 8 \%)$ & $201 / 1977(10 \cdot 20 \%)$ & $547 / 8908(6 \cdot 1 \%)$ & $46 / 239(19 \cdot 2 \%)$ & $722 / 10954(6 \cdot 6 \%)$ \\
\hline Cirrhosis & $12 / 11422(0 \cdot 1 \%)$ & $5 / 1977(0 \cdot 3 \%)$ & $5 / 8908(0 \cdot 1 \%)$ & $0 / 239(0 \%)$ & $11 / 10954(0 \cdot 1 \%)$ \\
\hline Metastatic cancer & $142 / 11422(1 \cdot 2 \%)$ & $32 / 1977(1 \cdot 6 \%)$ & $103 / 8908(1 \cdot 2 \%)$ & $11 / 239(4 \cdot 6 \%)$ & $129 / 10954(1 \cdot 2 \%)$ \\
\hline
\end{tabular}




\begin{tabular}{|c|c|c|c|c|c|}
\hline Hypertension & $1863 / 11422(16 \cdot 3 \%)$ & $377 / 1977(19 \cdot 1 \%)$ & $1406 / 8908(15 \cdot 8 \%)$ & $77 / 239(32 \cdot 2 \%)$ & $1767 / 10954(16 \cdot 1 \%)$ \\
\hline Stroke or Transient ischaemic attack & $91 / 11422(0 \cdot 8 \%)$ & $36 / 1977(1 \cdot 8 \%)$ & $48 / 8908(0 \cdot 5 \%)$ & $8 / 239(3 \cdot 3 \%)$ & $82 / 10954(0 \cdot 7 \%)$ \\
\hline COPD/Asthma & $375 / 11422(3 \cdot 3 \%)$ & 75/1977 (3.8\%) & $274 / 8908(3 \cdot 1 \%)$ & $13 / 239(5 \cdot 4 \%)$ & $357 / 10954(3 \cdot 3 \%)$ \\
\hline HIV positive/AIDS & $1253 / 11422(11 \cdot 0 \%)$ & $222 / 1977(11 \cdot 2 \%)$ & 986/8908 (11·1\%) & $18 / 239(7 \cdot 5 \%)$ & $1224 / 10954(11 \cdot 2 \%)$ \\
\hline Chronic renal disease & $171 / 11422(1 \cdot 5 \%)$ & $46 / 1977(2 \cdot 3 \%)$ & $111 / 8908(1 \cdot 2 \%)$ & $14 / 239(5 \cdot 9 \%)$ & $154 / 10954(1 \cdot 4 \%)$ \\
\hline
\end{tabular}

Data are mean (SD), median (25 $/ 75^{\text {th }}$ percentile) or $\mathrm{n}$ (proportion). Denominators vary with the completeness of the data. Odds ratios were constructed for in-hospital

complications and mortality with univariate binary logistic regression analysis. The denominator for each group is shown. $\mathrm{CI}=$ confidence interval. ASA=American Society

of Anesthesiologists. GIT= gastrointestinal. $\mathrm{COPD}=$ chronic obstructive pulmonary disease. HIV=human immunodeficiency virus. AIDS=acquired immunodeficiency syndrome. 
Table 2. Postoperative outcomes in the African Surgical Outcomes Study. Data presented as n (\%).

\begin{tabular}{|c|c|c|c|}
\hline Outcome & Number of patients & $\begin{array}{l}\text { Patients admitted to critical care } \\
\text { immediately after surgery }\end{array}$ & $\begin{array}{l}\text { Patients not admitted to critical care } \\
\text { immediately after surgery }\end{array}$ \\
\hline \multicolumn{4}{|l|}{ All surgeries } \\
\hline Mortality & 239/11193 (2·1) & 108/1198 (9·0) & $130 / 9960(1 \cdot 3)$ \\
\hline Complications & $1977 / 10885(18 \cdot 2)$ & $495 / 1971(25 \cdot 1)$ & $1476 / 9705(15 \cdot 2)$ \\
\hline Critical care admission to treat complications & $321 / 1972(16 \cdot 3)$ & $255 / 493 *(51 \cdot 7)$ & $64 / 1473 \dagger(4 \cdot 3)$ \\
\hline Death following a postoperative complication & $188 / 1970(9 \cdot 5)$ & $96 / 493 *(19 \cdot 5)$ & $92 / 1472 \dagger(6 \cdot 3)$ \\
\hline \multicolumn{4}{|l|}{ Elective surgery only } \\
\hline Mortality & $48 / 4792(1 \cdot 0)$ & $12 / 376(3 \cdot 2)$ & $35 / 4403(0 \cdot 8)$ \\
\hline Complications & $624 / 4658(13 \cdot 4)$ & $140 / 367(38 \cdot 1)$ & $482 / 4282(11 \cdot 3)$ \\
\hline Critical care admission to treat complications & $86 / 622(13 \cdot 8)$ & $68 / 140 *(48 \cdot 6)$ & $17 / 480 \dagger(3 \cdot 5)$ \\
\hline Death following a postoperative complication & $30 / 620(4 \cdot 8)$ & $10 / 139 *(7 \cdot 2)$ & $20 / 480 \dagger(4 \cdot 2)$ \\
\hline
\end{tabular}

Denominators vary with the completeness of the data. *total number admitted to critical care immediately following surgery; $\dagger$ total number not admitted to critical care immediately after surgery 
Table 3. Postoperative complications in the African Surgical Outcomes Study (ASOS). Data are presented as n (\%).

\begin{tabular}{|c|c|c|c|c|c|c|}
\hline Complications & $\begin{array}{c}\text { Number } \\
\text { of } \\
\text { patients }\end{array}$ & Mild & Moderate & Severe & $\begin{array}{l}\text { Mortality for all patients that } \\
\text { developed complications }\end{array}$ & $\begin{array}{c}\text { Mortality for elective surgical } \\
\text { patients that developed } \\
\text { complications }\end{array}$ \\
\hline \multicolumn{7}{|l|}{ Infectious complications } \\
\hline Superficial surgical site & 10968 & $402(3 \cdot 5)$ & $303(2 \cdot 7)$ & $82(0 \cdot 7)$ & $41 / 787(5 \cdot 21)$ & $5 / 245(2 \cdot 0)$ \\
\hline Deep surgical site & 10969 & $77(0 \cdot 7)$ & $141(1 \cdot 2)$ & $110(1 \cdot 0)$ & $43 / 328(13 \cdot 1)$ & $3 / 78(3 \cdot 8)$ \\
\hline Body cavity & 10968 & $25(0 \cdot 2)$ & $55(0 \cdot 5)$ & $45(0 \cdot 4)$ & $28 / 125(22 \cdot 4)$ & $1 / 21(4 \cdot 8)$ \\
\hline Pneumonia & 10968 & $51(0 \cdot 5)$ & $85(1 \cdot 2)$ & $49(0 \cdot 4)$ & $56 / 185(30 \cdot 3)$ & $5 / 50(10 \cdot 0)$ \\
\hline Urinary tract & 10967 & $64(0 \cdot 6)$ & $29(0 \cdot 3)$ & $19(0 \cdot 2)$ & 20/112 (17.9) & $2 / 38(6 \cdot 3)$ \\
\hline Bloodstream & 10970 & $27(0 \cdot 2)$ & $50(0 \cdot 5)$ & $64(0 \cdot 6)$ & $58 / 141(41 \cdot 1)$ & $6 / 32(18 \cdot 8)$ \\
\hline \multicolumn{5}{|c|}{ Total number of patients with infectious complications } & $112 / 1156(9 \cdot 7)$ & $12 / 354(3 \cdot 4)$ \\
\hline \multicolumn{7}{|c|}{ Cardiovascular complications } \\
\hline Myocardial infarction & 10969 & $7(0 \cdot 1)$ & $1(0 \cdot 0)$ & $3(0 \cdot 0)$ & $3 / 11(27 \cdot 3)$ & $0 / 2(0 \cdot 0)$ \\
\hline Arrhythmia & 10969 & $16(0 \cdot 1)$ & $14(0 \cdot 1)$ & $10(0 \cdot 1)$ & $11 / 40(27 \cdot 5)$ & $1 / 14(7 \cdot 1)$ \\
\hline Pulmonary oedema & 10969 & $17(0 \cdot 1)$ & $13(0 \cdot 1)$ & $8(0 \cdot 1)$ & $17 / 38(44 \cdot 7)$ & $1 / 7(14 \cdot 3)$ \\
\hline Pulmonary embolism & 10969 & $3(0 \cdot 0)$ & $1(0 \cdot 0)$ & $11(0 \cdot 1)$ & $11 / 15(73 \cdot 3)$ & $5 / 8(62 \cdot 5)$ \\
\hline Stroke & 10921 & $6(0 \cdot 1)$ & $6(0 \cdot 1)$ & $8(0 \cdot 1)$ & $6 / 20(30 \cdot 0)$ & $1 / 7(14 \cdot 3)$ \\
\hline Cardiac arrest & 10945 & & & $113(1 \cdot 0)$ & $101 / 113(89 \cdot 4)$ & $13 / 19(68 \cdot 4)$ \\
\hline \multicolumn{5}{|c|}{ Total number of patients with cardiovascular complications } & $110 / 190(57 \cdot 9)$ & $15 / 48(31 \cdot 3)$ \\
\hline \multicolumn{7}{|l|}{ Other complications } \\
\hline Gastrointestinal bleed & 10966 & $20(0 \cdot 2)$ & $12(0 \cdot 1)$ & $7(0 \cdot 1)$ & $13 / 39(33 \cdot 3)$ & $1 / 11(9 \cdot 1)$ \\
\hline Acute kidney injury & 10967 & $50(0 \cdot 4)$ & $54(0 \cdot 5)$ & $42(0 \cdot 4)$ & $51 / 146(34 \cdot 9)$ & 4/31 (12·9) \\
\hline Postoperative bleed & 10968 & $98(0 \cdot 9)$ & $404(3 \cdot 5)$ & $59(0 \cdot 5)$ & $39 / 561(7 \cdot 0)$ & $5 / 159(3 \cdot 1)$ \\
\hline ARDS & 10966 & $14(0 \cdot 1)$ & $19(0 \cdot 2)$ & $19(0 \cdot 2)$ & $26 / 52(50 \cdot 0)$ & $4 / 14(28 \cdot 6)$ \\
\hline Anastomotic leak & 10961 & $9(0 \cdot 1)$ & $14(0 \cdot 1)$ & $23(0 \cdot 2)$ & $16 / 46(34 \cdot 8)$ & $3 / 19(15 \cdot 8)$ \\
\hline All others & 10936 & $151(1 \cdot 3)$ & $147(1 \cdot 3)$ & $83(0 \cdot 7)$ & $40 / 381(10 \cdot 5)$ & $5 / 131(3 \cdot 8)$ \\
\hline \multicolumn{5}{|c|}{ Total number of patients with other complications } & $112 / 1044(10 \cdot 7)$ & $14 / 314(4 \cdot 5)$ \\
\hline \multicolumn{5}{|c|}{ Total number of patients with complications } & $188 / 1970(9 \cdot 5)$ & $30 / 620(4 \cdot 8)$ \\
\hline
\end{tabular}

Denominators vary with the completeness of the data. ARDS acute respiratory distress syndrome 
Table 4. The association between the primary indication for surgery and postoperative complications and in-hospital mortality. Data presented as $\mathbf{n}(\%)$

\begin{tabular}{|c|c|c|c|c|c|c|c|c|c|}
\hline & $\begin{array}{l}\text { All patients } \\
(\mathrm{n}=10842)\end{array}$ & $\begin{array}{c}\text { Complications } \\
(\mathrm{n}=1973)\end{array}$ & $\begin{array}{c}\text { No complications } \\
(\mathbf{n}=\mathbf{8 8 6 9})\end{array}$ & $\begin{array}{c}\text { Odds ratio (95\% } \\
\text { CI) }\end{array}$ & $P$ value & $\begin{array}{c}\text { Died } \\
(n=238)\end{array}$ & $\begin{array}{c}\text { Survived } \\
(\mathrm{n}=10876)\end{array}$ & $\begin{array}{c}\text { Odds ratio (95\% } \\
\text { CI) }\end{array}$ & $\begin{array}{c}\mathbf{P} \\
\text { value }\end{array}$ \\
\hline $\begin{array}{l}\text { Non-communicable } \\
\text { disease }\end{array}$ & $4577(42 \cdot 2 \%)$ & $736(37 \cdot 3 \%)$ & $4577(42 \cdot 2 \%)$ & Reference & & $96(40 \cdot 3 \%)$ & $\begin{array}{c}4607 \\
(42 \cdot 4 \%)\end{array}$ & Reference & \\
\hline Acute infection & $1380(12 \cdot 7 \%)$ & $398(20 \cdot 2 \%)$ & $982(12 \cdot 7 \%)$ & $2 \cdot 12(1 \cdot 84-2 \cdot 44)$ & $<0 \cdot 0001$ & $63(26 \cdot 5 \%)$ & $\begin{array}{c}1352 \\
(12 \cdot 4 \%)\end{array}$ & $2 \cdot 24(1 \cdot 62-3 \cdot 09)$ & $<0 \cdot 0001$ \\
\hline Trauma & $1929(17 \cdot 8 \%)$ & $405(20 \cdot 5 \%)$ & $1524(17 \cdot 8 \%)$ & $1 \cdot 39(1 \cdot 21-1 \cdot 59)$ & $<0 \cdot 0001$ & $61(25 \cdot 6 \%)$ & $\begin{array}{c}1947 \\
(17 \cdot 9 \%)\end{array}$ & $1 \cdot 50(1 \cdot 09-2 \cdot 08)$ & $0 \cdot 0140$ \\
\hline Caesarean section & $2956(27 \cdot 3 \%)$ & $434(22 \cdot 0 \%)$ & $2522(28 \cdot 4 \%)$ & $0 \cdot 90(0 \cdot 79-1 \cdot 02)$ & $0 \cdot 10$ & $18(7 \cdot 6 \%)$ & $\begin{array}{c}2970 \\
(27 \cdot 3 \%) \\
\end{array}$ & $0 \cdot 29(0 \cdot 18-0 \cdot 48)$ & $<0 \cdot 0001$ \\
\hline
\end{tabular}



Figure 2. African Surgical Outcomes Study (ASOS) country, hospital and patient recruitment

11463 patients entered into database

Too young (18)/Duplicates (23)

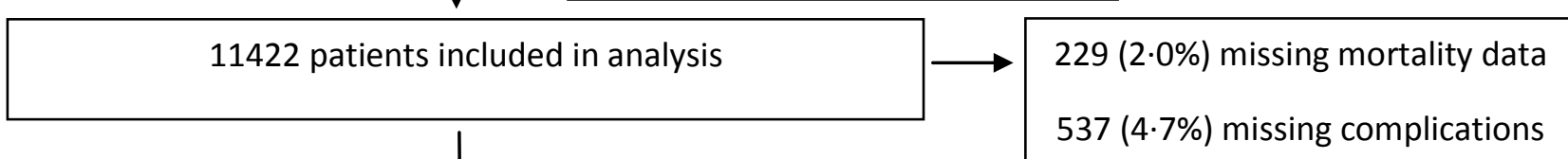

\section{Countries fulfilling per-protocol data inclusion criteria}

(11 Countries, 175 Hospitals, 9024 Patients)

- $\quad$ DRC 24/24 representative hospitals, 315 patients

- $\quad$ Gambia 5/5 representative hospitals, 82 patients

- Madagascar 8/8 representative hospitals, 192 patients

- $\quad$ Mali 9/9 representative hospitals, 329 patients

- Mauritius 6/6 representative hospitals, 418 patients

- Namibia $18 / 18$ representative hospitals, 325 patients

- $\quad$ Niger $10 / 10$ representative hospitals, 186 patients

- $\quad$ Nigeria 10/10 representative hospitals, 395 patients

- $\quad$ South Africa 53/54 representative hospitals, 5522 patients

- Uganda $10 / 10$ representative hospitals, 620 patients

- Zimbabwe 20/21 representative hospitals, 640 patients
Countries not fulfilling per-protocol data inclusion criteria (14 Countries, 72 Hospitals, 2398 patients)

- $\quad$ Algeria 7/7 representative hospitals, 184 patients

- $\quad$ Benin 5/13 representative hospitals, 220 patients

- $\quad$ Burundi 5/7 representative hospitals, 127 patients

- $\quad$ Cameroon 5/5 representative hospitals, 223 patients

- $\quad$ Congo $1 / 1$ representative hospitals, 3 patients

- $\quad$ Egypt $0 / 1 \mathrm{~h}$ representative hospitals, 10 patients

- $\quad$ Ethiopia 3/6 representative hospitals, 252 patients

- Ghana 2/5 representative hospitals, 225 patients

- $\quad$ Kenya $5 / 5$ representative hospitals, 324 patients

- Libya $9 / 10$ representative hospitals, 667 patients

- $\quad$ Senegal 0/1 representative hospitals, 7 patients

- Tanzania $2 / 4$ representative hospitals, 97 patients

- Togo $1 / 1$ representative hospitals, 19 patients

- Zambia 6 hospitals, 4 hospitals $>90 \%$ recruitment 
Figure 3. Surgical mortality following elective surgery in high-income, low-middle income, and African countries

$6 \%$

$5 \%$

$4 \%$

$3 \%$

$2 \%$

$1 \%$

$0 \%$

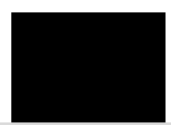

All-cause postoperative mortality

HIC ISOS
Mortality following postoperative complications

LMIC ISOS

- ASOS

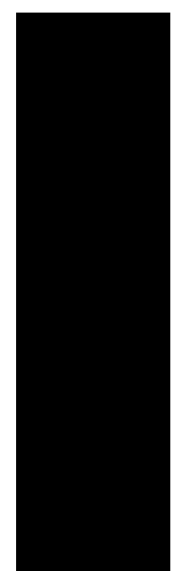

ISOS International Surgical Outcomes Study, ASOS African Surgical Outcomes Study, HIC high income countries, LMIC low-middle income countries 
Supplementary Table 1. The country-specific reported mortality, postoperative complications, critical care admission and duration of

\section{hospital stay}

\begin{tabular}{|c|c|c|c|c|c|c|c|c|}
\hline Country & Patients & $\begin{array}{c}\text { In-hospital } \\
\text { mortality }\end{array}$ & $\begin{array}{c}\text { \% In-hospital mortality } \\
(95 \% \mathrm{CI})^{*}\end{array}$ & $\begin{array}{l}\text { Postoperative } \\
\text { complications }\end{array}$ & $\begin{array}{c}\text { \% Postoperative } \\
\text { complications (95\% CI) }\end{array}$ & $\begin{array}{c}\text { Critical care } \\
\text { admission }\end{array}$ & $\begin{array}{c}\% \text { Critical care } \\
\text { admission }(95 \% \mathrm{CI}) *\end{array}$ & $\begin{array}{c}\text { Median days in hospital } \\
\left(25^{\text {th }} / 75^{\text {th }} \text { centile }\right)\end{array}$ \\
\hline Algeria & $184(1 \cdot 6 \%)$ & $7 / 184$ & $3 \cdot 8 \%(1 \cdot 0-6 \cdot 6)$ & $58 / 183$ & $31 \cdot 7 \%(25 \cdot 0-38 \cdot 4)$ & 15/184 & $8 \cdot 2 \%(4 \cdot 2-12 \cdot 1)$ & $5(3-7)$ \\
\hline Benin & $220(1 \cdot 9 \%)$ & $2 / 173$ & $1 \cdot 2 \%(0-2 \cdot 7)$ & $24 / 132$ & $18 \cdot 2 \%(11 \cdot 6-24 \cdot 8)$ & $42 / 157$ & $26 \cdot 8 \%(19 \cdot 8-33 \cdot 7)$ & $5(4-8)$ \\
\hline Burundi & $127(1 \cdot 1 \%)$ & $1 / 74$ & $1 \cdot 4 \%(0-4 \cdot 0)$ & $14 / 74$ & $18 \cdot 9 \%(10 \cdot 0-27 \cdot 8)$ & $0 / 74$ & & $4(3-7)$ \\
\hline Cameroon & $223(2 \cdot 0 \%)$ & $3 / 223$ & $1 \cdot 3 \%(0-2 \cdot 9)$ & $29 / 221$ & $13 \cdot 1 \%(8 \cdot 7-17 \cdot 6)$ & $2 / 223$ & $0 \cdot 9 \%(0-2 \cdot 1)$ & $3(2-5)$ \\
\hline Congo & $3(0 \%)$ & $0 / 3$ & & $0 / 3$ & & $0 / 3$ & & $3(2-4)$ \\
\hline DRC & $315(2 \cdot 8 \%)$ & $12 / 315$ & $3 \cdot 8 \%(1 \cdot 7-5 \cdot 9)$ & 64/314 & $20 \cdot 4 \%(15 \cdot 9-24 \cdot 8)$ & $17 / 315$ & $5 \cdot 4 \%(2 \cdot 9-7 \cdot 9)$ & $8(5-12)$ \\
\hline Egypt & $10(0 \cdot 1 \%)$ & $0 / 9$ & & $8 / 10$ & $80 \%(55 \cdot 2-100)$ & $0 / 10$ & & $2(2-4)$ \\
\hline Ethiopia & $252(2 \cdot 2 \%)$ & $6 / 247$ & $2 \cdot 4 \%(0 \cdot 5-4 \cdot 3)$ & $55 / 232$ & $23 \cdot 7 \%(18 \cdot 2-29 \cdot 2)$ & $7 / 250$ & $2 \cdot 8 \%(0 \cdot 8-4 \cdot 8)$ & $3(2-7)$ \\
\hline Gambia & $82(0 \cdot 7 \%)$ & $3 / 82$ & $3 \cdot 7 \%(0-7 \cdot 7)$ & $20 / 82$ & $24 \cdot 4 \%(15 \cdot 1-33 \cdot 7)$ & $3 / 82$ & $3 \cdot 7 \%(0-7 \cdot 7)$ & $4(3-7)$ \\
\hline Ghana & $225(2 \cdot 0 \%)$ & $2 / 146$ & $1 \cdot 4 \%(0 \cdot 5-3 \cdot 3)$ & $26 / 147$ & $17 \cdot 7 \%(11 \cdot 5-23 \cdot 9)$ & $2 / 147$ & $1 \cdot 4 \%(0-3 \cdot 2)$ & $5(3-7)$ \\
\hline Kenya & $324(2 \cdot 8 \%)$ & $5 / 324$ & $1 \cdot 5 \%(0 \cdot 2-2 \cdot 9)$ & $80 / 321$ & $24 \cdot 9 \%(20 \cdot 2-29 \cdot 7)$ & $10 / 323$ & $3 \cdot 1 \%(1 \cdot 2-5 \cdot 0)$ & $4(3-8)$ \\
\hline Libya & $667(5 \cdot 8 \%)$ & $5 / 664$ & $0 \cdot 8 \%(0 \cdot 1-1 \cdot 4)$ & $126 / 663$ & $19 \cdot 0 \%(16 \cdot 0-22 \cdot 0)$ & $35 / 663$ & $5 \cdot 3 \%(3 \cdot 6-7 \cdot 0)$ & $2(1-3)$ \\
\hline Madagascar & $192(1 \cdot 7 \%)$ & $2 / 192$ & $1 \cdot 0 \%(0-2 \cdot 5)$ & $42 / 192$ & $21 \cdot 9 \%(16 \cdot 0-27 \cdot 7)$ & $18 / 192$ & $9 \cdot 4 \%(5 \cdot 3-13 \cdot 5)$ & $5(3-6)$ \\
\hline Mali & $329(2 \cdot 9 \%)$ & $11 / 329$ & $3 \cdot 3 \%(1 \cdot 4-5 \cdot 3)$ & $72 / 323$ & $22 \cdot 3 \%(17 \cdot 8-26 \cdot 8)$ & $12 / 328$ & $3 \cdot 7 \%(1 \cdot 6-5 \cdot 7)$ & $4(3-6)$ \\
\hline Mauritius & $418(3 \cdot 7 \%)$ & $8 / 418$ & $1 \cdot 9 \%(0 \cdot 6-3 \cdot 2)$ & $52 / 417$ & $12 \cdot 5 \%(9 \cdot 3-15 \cdot 6)$ & $16 / 418$ & $3 \cdot 8 \%(2 \cdot 0-5 \cdot 7)$ & $3(1-5)$ \\
\hline Namibia & $325(2 \cdot 8 \%)$ & $12 / 325$ & $3 \cdot 7 \%(1 \cdot 6-5 \cdot 7)$ & $59 / 323$ & $18 \cdot 3 \%(14 \cdot 1-22 \cdot 5)$ & $14 / 325$ & $4 \cdot 3 \%(2 \cdot 1-6 \cdot 5)$ & $4(2-6)$ \\
\hline Niger & $186(1 \cdot 6 \%)$ & $2 / 186$ & $1 \cdot 1 \%(0-2 \cdot 6)$ & $71 / 186$ & $38 \cdot 2 \%(31 \cdot 2-45 \cdot 2)$ & $27 / 186$ & $14 \cdot 5 \%(0 \cdot 9-19 \cdot 6)$ & $5(3-8)$ \\
\hline Nigeria & $395(3 \cdot 5 \%)$ & $8 / 392$ & $2 \cdot 0 \%(0 \cdot 6-3 \cdot 4)$ & $67 / 379$ & $17 \cdot 7 \%(13 \cdot 8-21 \cdot 5)$ & $15 / 395$ & $3 \cdot 8 \%(1 \cdot 9-5 \cdot 7)$ & $6(4-9)$ \\
\hline Senegal & $7(0 \cdot 1 \%)$ & $1 / 7$ & $14 \cdot 3 \%(0-40 \cdot 2)$ & $3 / 7$ & $42 \cdot 9 \%(6 \cdot 2-79 \cdot 5)$ & $1 / 7$ & $14 \cdot 3 \%(0-40 \cdot 2)$ & $5(2-6)$ \\
\hline South Africa & $5522(48 \cdot 3 \%)$ & $132 / 5492$ & $2 \cdot 4 \%(2 \cdot 0-2 \cdot 8)$ & $810 / 5274$ & $15 \cdot 4 \%(14 \cdot 4-16 \cdot 3)$ & $220 / 5308$ & $4 \cdot 1 \%(3 \cdot 6-4 \cdot 7)$ & $3(2-5)$ \\
\hline Tanzania & $97(0 \cdot 8 \%)$ & $0 / 97$ & & $17 / 96$ & $17 \cdot 7 \%(10 \cdot 1-25 \cdot 3)$ & $21 / 97$ & $21 \cdot 6 \%(13 \cdot 4-28 \cdot 8)$ & $3(2-3)$ \\
\hline Togo & $19(0 \cdot 2 \%)$ & $0 / 18$ & & $0 / 19$ & & $0 / 11$ & & $10(7-19)$ \\
\hline Uganda & $620(5 \cdot 4 \%)$ & $7 / 619$ & $1 \cdot 1 \%(0 \cdot 3-2 \cdot 0)$ & $195 / 617$ & $31 \cdot 6 \%(27 \cdot 9-35 \cdot 3)$ & $7 / 619$ & $1 \cdot 1 \%(0 \cdot 3-2 \cdot 0)$ & $3(3-5)$ \\
\hline Zambia & $40(0 \cdot 4 \%)$ & $2 / 34$ & $5 \cdot 9 \%(0-13 \cdot 8)$ & $12 / 34$ & $35 \cdot 3 \%(19 \cdot 2-51 \cdot 4)$ & $3 / 34$ & $8 \cdot 8 \%(0-18 \cdot 4)$ & $4(3-6)$ \\
\hline Zimbabwe & $640(5 \cdot 6 \%)$ & $8 / 640$ & $1 \cdot 3 \%(0 \cdot 4-2 \cdot 1)$ & $72 / 635$ & $11 \cdot 3 \%(8 \cdot 9-13 \cdot 8)$ & $24 / 640$ & $3 \cdot 8 \%(2 \cdot 3-5 \cdot 2)$ & $3(3-4)$ \\
\hline All & 11422 & $239 / 11193$ & $2 \cdot 1 \%(1 \cdot 9-2 \cdot 4)$ & $1977 / 10885$ & $18 \cdot 2 \%(17 \cdot 4-18 \cdot 9)$ & $511 / 10991$ & $4 \cdot 6 \%(4 \cdot 3-5 \cdot 0)$ & $3(2-6)$ \\
\hline
\end{tabular}

Denominators vary with the completeness of the data. DRC Democratic Republic of the Congo; CI confidence interval

*The country specific crude mortality rates and complication rates are particularly unstable as the study was not powered to accurately determine the country specific mortality and complication rates. A country sample size of at least 3000 patients would be required for a relatively stable estimate of mortality and 1400 patients for a relatively stable estimate of postoperative complications. 
Supplementary Table 2. Multivariable model of in-hospital mortality per-protocol analysis.

\begin{tabular}{|c|c|c|c|}
\hline & Odds ratio (OR) & $95 \%$ confidence interval (CI) & P-value \\
\hline Intercept & $0 \cdot 002$ & $0 \cdot 000-0 \cdot 046$ & $<0 \cdot 0001$ \\
\hline \multicolumn{4}{|l|}{ Patient factors } \\
\hline Age spline 1 & $0 \cdot 990$ & $0 \cdot 869-1 \cdot 129$ & $0 \cdot 89$ \\
\hline Age spline 2 & $1 \cdot 125$ & $0 \cdot 133-9 \cdot 503$ & $0 \cdot 91$ \\
\hline Age spline 3 & 0.985 & $0 \cdot 005-185 \cdot 709$ & $1 \cdot 00$ \\
\hline Age spline 4 & $0 \cdot 773$ & $0 \cdot 017-34 \cdot 282$ & $0 \cdot 89$ \\
\hline ASA 1 & Reference & & \\
\hline ASA 2 & $1 \cdot 438$ & $0 \cdot 910-2 \cdot 273$ & $0 \cdot 12$ \\
\hline ASA 3 & $3 \cdot 627$ & $2 \cdot 269-5 \cdot 799$ & $<0 \cdot 0001$ \\
\hline ASA 4 or 5 & $10 \cdot 153$ & $5 \cdot 986-17 \cdot 222$ & $<0 \cdot 0001$ \\
\hline \multicolumn{4}{|l|}{ Surgical factors } \\
\hline Elective surgery & Reference & & \\
\hline Urgent surgery & $3 \cdot 296$ & $2 \cdot 155-5 \cdot 041$ & $<0 \cdot 0001$ \\
\hline Emergent surgery & $4 \cdot 397$ & $2 \cdot 864-6 \cdot 752$ & $<0 \cdot 0001$ \\
\hline Minor surgery & Reference & & \\
\hline Intermediate surgery & $1 \cdot 699$ & $1 \cdot 038-2 \cdot 782$ & $0 \cdot 04$ \\
\hline Major surgery & $2 \cdot 595$ & $1 \cdot 536-4 \cdot 385$ & $0 \cdot 0004$ \\
\hline Cardiothoracic and vascular surgery & $1 \cdot 773$ & $0 \cdot 983-3 \cdot 197$ & $0 \cdot 06$ \\
\hline Ear nose and throat & $2 \cdot 279$ & $1 \cdot 062-4 \cdot 892$ & $0 \cdot 03$ \\
\hline Gastrointestinal and hepatobiliary & $2 \cdot 599$ & $1 \cdot 572-4 \cdot 296$ & $0 \cdot 0002$ \\
\hline Gynaecology and obstetrics & $0 \cdot 329$ & $0 \cdot 170-0 \cdot 634$ & $0 \cdot 0009$ \\
\hline Neurosurgery & $2 \cdot 794$ & $1 \cdot 378-5 \cdot 663$ & $0 \cdot 0044$ \\
\hline Other & $1 \cdot 133$ & $0 \cdot 508-2 \cdot 528$ & $0 \cdot 76$ \\
\hline Plastics and breast & 1.576 & $0 \cdot 773-3 \cdot 212$ & $0 \cdot 21$ \\
\hline Urology & $1 \cdot 684$ & $0 \cdot 803-3 \cdot 535$ & $0 \cdot 17$ \\
\hline \multicolumn{4}{|l|}{ Countries } \\
\hline A & $2 \cdot 006$ & $1 \cdot 029-3 \cdot 913$ & 0.04 \\
\hline
\end{tabular}




\begin{tabular}{|l|l|r|}
\hline B & $1 \cdot 080$ & $0 \cdot 301-3 \cdot 875$ \\
\hline C & $0 \cdot 387$ & $0 \cdot 090-1 \cdot 665$ \\
\hline E & $1 \cdot 892$ & $0 \cdot 952-3 \cdot 761$ \\
\hline F & $1 \cdot 062$ & $0 \cdot 491-2 \cdot 295$ \\
\hline G & $2 \cdot 525$ & $0.292-4 \cdot 933$ \\
\hline H & $0 \cdot 407$ & $0 \cdot 094-1 \cdot 765$ \\
\hline I & $0 \cdot 667$ & $0 \cdot 307-1 \cdot 446$ \\
\hline J & $0 \cdot 821$ & $0 \cdot 361-1 \cdot 867$ \\
\hline
\end{tabular}

ASA American Society of Anesthesiologists; A-J anonymised countries 
Supplementary Table 3. Comparison between the elective surgery patients of the African Surgical Outcomes Study (per-protocol, representative sample) and the International Surgical Outcomes Study

\begin{tabular}{|c|c|c|}
\hline & ASOS (n=3868) & ISOS $(n=44814)$ \\
\hline \multicolumn{3}{|l|}{ Risk factors } \\
\hline Age & $44 \cdot 6(17 \cdot 0)$ & $55 \cdot 3(17 \cdot 1)$ \\
\hline ASA 1 & $1737(44 \cdot 9)$ & $11227(25 \cdot 1)$ \\
\hline Minor surgery & $1140(29 \cdot 5)$ & $672(8 \cdot 0)$ \\
\hline \multicolumn{3}{|l|}{ Outcomes } \\
\hline Mortality & $42(1 \cdot 1)$ & $207(0 \cdot 5)$ \\
\hline Complications & $468(12 \cdot 1)$ & $7508(16 \cdot 8)$ \\
\hline Mortality following complications & $26 / 468(5 \cdot 6)$ & $207 / 7508(2 \cdot 8)$ \\
\hline
\end{tabular}

Data are mean (SD) or n (proportion). ASOS= African Surgical Outcomes Study. ISOS= International Surgical Outcomes Study. ASA=American Society of Anesthesiologists. 
Supplementary Table 4. Hospital facilities and resources data $(n=166)$ of the per-protocol representative country sample analysis. Data presented as $\mathbf{n}(\%)$ or median $\left[25^{\text {th }} / 75^{\text {th }}\right.$ centile]

\begin{tabular}{|c|c|}
\hline Hospital facilities and resources & n (\%) or median [25th/75th centile] \\
\hline Population served by the hospital & 881500 [200 000-2000 000] \\
\hline University affiliated hospital & $70 / 162(43 \cdot 2)$ \\
\hline Government funding/ private funding/ government and private funding & $129(77 \cdot 7) / 26(15 \cdot 7) / 11(6 \cdot 6)$ \\
\hline \multicolumn{2}{|l|}{ Type of hospital } \\
\hline Primary-level hospital & $36(21 \cdot 7)$ \\
\hline Secondary-level hospital & $59(35 \cdot 5)$ \\
\hline Tertiary-level hospital & $71(42 \cdot 3)$ \\
\hline \multicolumn{2}{|l|}{ Hospital resources } \\
\hline Hospital beds & 300 [135-525] \\
\hline Operating rooms & $4[2-7]$ \\
\hline Critical care beds allowing invasive ventilation & $3[0-6]$ \\
\hline Full time specialist surgeons & $3[1-7]$ \\
\hline Full time specialist anaesthesiologists & $1[1-5]$ \\
\hline Full time specialist obstetricians & $2[0-5]$ \\
\hline Combined number of specialist surgeons, anaesthesiologists and obstetricians & $7[2-16]$ \\
\hline Combined number of specialist surgeons, anaesthesiologists and obstetricians/100,000 population & $0 \cdot 7[0 \cdot 2-1 \cdot 9]$ \\
\hline
\end{tabular}


Supplementary Table 5. Description of the per-protocol representative sample of the African Surgical Outcomes Study (ASOS) patient cohort.

\begin{tabular}{|c|c|c|c|c|c|}
\hline & $\begin{array}{l}\text { All patients } \\
(\mathrm{n}=9024)\end{array}$ & $\begin{array}{l}\text { Patients with } \\
\text { complications (n=1525) }\end{array}$ & $\begin{array}{l}\text { Patients with no } \\
\text { complications }(\mathrm{n}=7218)\end{array}$ & $\begin{array}{l}\text { Patients who died } \\
(\mathrm{n}=205)\end{array}$ & $\begin{array}{l}\text { Patients who survived } \\
(\mathrm{n}=8785)\end{array}$ \\
\hline Age (years) & $\begin{array}{l}39 \cdot 0(16 \cdot 4) \\
34 \cdot 0(26 \cdot 0-49 \cdot 0)\end{array}$ & $\begin{array}{l}41 \cdot 0(17 \cdot 5) \\
36 \cdot 0(27 \cdot 0-53 \cdot 0)\end{array}$ & $\begin{array}{l}38 \cdot 5(16 \cdot 1) \\
33 \cdot 0(26 \cdot 0-48 \cdot 0)\end{array}$ & $\begin{array}{l}50 \cdot 7(19 \cdot 2) \\
52 \cdot 0(33 \cdot 5-65 \cdot 0)\end{array}$ & $\begin{array}{l}38 \cdot 7(16 \cdot 2) \\
34 \cdot 0(26 \cdot 0-48 \cdot 0)\end{array}$ \\
\hline Male & $3025 / 9024(33 \cdot 5 \%)$ & $617 / 1525(40 \cdot 5 \%)$ & 2278/7218 (31·6\%) & $103 / 205(50 \cdot 2 \%)$ & 2909/8785 (33·1\%) \\
\hline Current smoker & $1520 / 8995(16 \cdot 8 \%)$ & 252/1521 (16·6\%) & 1204/7195 (16·7\%) & $33 / 202(16 \cdot 9 \%)$ & $1481 / 8760(16 \cdot 95 \%)$ \\
\hline \multicolumn{6}{|l|}{ ASA category } \\
\hline 1 & 4196/9016 (46.5\%) & $534 / 1523(35 \cdot 1 \%)$ & $3543 / 7214(49 \cdot 1 \%)$ & $35 / 205(17 \cdot 1 \%)$ & 4145/8778 (47·2\%) \\
\hline 2 & $3515 / 9016(39 \cdot 0 \%)$ & $575 / 1523(37 \cdot 8 \%)$ & 2834/7214 (39·3\%) & $52 / 205(25 \cdot 4 \%)$ & $3452 / 8778(39 \cdot 3 \%)$ \\
\hline 3 & $1084 / 9016(12 \cdot 0 \%)$ & $306 / 1523(20 \cdot 1 \%)$ & 744/7214 (10·3\%) & $70 / 205(34 \cdot 1 \%)$ & $1010 / 8778(11 \cdot 5 \%)$ \\
\hline 4 & $213 / 9016(2 \cdot 4 \%)$ & $103 / 1523(6 \cdot 8 \%)$ & $91 / 7214(1 \cdot 3 \%)$ & $42 / 205(20 \cdot 5 \%)$ & 170/8778 (1.9\%) \\
\hline 5 & $8 / 9016(0 \cdot 1 \%)$ & $5 / 1523(0 \cdot 3 \%)$ & $2 / 7214(0 \%)$ & $6 / 205(2 \cdot 9 \%)$ & $1 / 8778(0 \%)$ \\
\hline \multicolumn{6}{|l|}{ Grade of surgery } \\
\hline Minor & $2105 / 9010(23 \cdot 3 \%)$ & 228/1521 (15·0\%) & 1789/7209 (24·8\%) & $23 / 205(11 \cdot 2 \%)$ & 2065/8772 (23·5\%) \\
\hline Intermediate & $4536 / 9010(50 \cdot 3 \%)$ & 654/1521 (43·0\%) & 3758/7209 (52·1\%) & $86 / 205(42 \cdot 0 \%)$ & $4442 / 8772(50 \cdot 6 \%)$ \\
\hline Major & $2369 / 9010(26 \cdot 3 \%)$ & 639/1521 (42·0\%) & $1662 / 7209(23 \cdot 1 \%)$ & $96 / 205(46 \cdot 8 \%)$ & $2265 / 8772(25 \cdot 8 \%)$ \\
\hline \multicolumn{6}{|l|}{ Urgency of surgery } \\
\hline Elective & 3868/9014 (42·9\%) & $468 / 1520(30 \cdot 8 \%)$ & $3271 / 7213(45 \cdot 3 \%)$ & $42 / 205(20 \cdot 5 \%)$ & $3810 / 8775(43 \cdot 4 \%)$ \\
\hline Urgent & 2116/9014 (23·4\%) & $401 / 1520(26 \cdot 4 \%)$ & 1639/7213 (22·7\%) & $66 / 205(32 \cdot 2 \%)$ & $2040 / 8775(23 \cdot 2 \%)$ \\
\hline Emergency & 3030/9014 (33·6\%) & $651 / 1520(42 \cdot 8 \%)$ & 2303/7213 (31.9\%) & 97/205 (47·3\%) & 2925/8775 (33·3\%) \\
\hline \multicolumn{6}{|l|}{ Surgical speciality } \\
\hline Orthopaedic & $1472 / 9022(16 \cdot 3 \%)$ & 235/1525 (15·4\%) & 1372/7216 (15·5\%) & $26 / 205(12 \cdot 7 \%)$ & 1433/8783 (16·3\%) \\
\hline Breast & $187 / 9022(2 \cdot 1 \%)$ & $20 / 1525(1 \cdot 3 \%)$ & $162 / 7216(2 \cdot 2 \%)$ & $2 / 205(1 \cdot 0 \%)$ & $185 / 8783(2 \cdot 1 \%)$ \\
\hline Obstetrics & 2879/9022 (31.9\%) & $395 / 1525(25 \cdot 9 \%)$ & $2433 / 7216(33 \cdot 7 \%)$ & $15 / 205(7 \cdot 3 \%)$ & 2857/8783 (32-5\%) \\
\hline Gynaecology & $1118 / 9022(12 \cdot 4 \%)$ & $133 / 1525(8 \cdot 7 \%)$ & $954 / 7216(13 \cdot 2 \%)$ & $7 / 205(3 \cdot 4 \%)$ & 1110/8783 (12·6\%) \\
\hline Upper GIT & $222 / 9022(2 \cdot 5 \%)$ & $73 / 1525(4 \cdot 8 \%)$ & $145 / 7216(2 \cdot 0 \%)$ & $25 / 205(12 \cdot 2 \%)$ & $197 / 8783(2 \cdot 2 \%)$ \\
\hline Lower GIT & 723/9022 (8·0\%) & 174/1525 (11·4\%) & $528 / 7216(7 \cdot 3 \%)$ & $39 / 205(19 \cdot 0 \%)$ & 682/8783 (7·8\%) \\
\hline Hepatobiliary & $120 / 9022(1 \cdot 3 \%)$ & $24 / 1525(1 \cdot 6 \%)$ & $95 / 7216(1 \cdot 3 \%)$ & $4 / 205(2 \cdot 0 \%)$ & $116 / 8783(1 \cdot 3 \%)$ \\
\hline Urology and kidney & 477/9022 (5·3\%) & $87 / 1525(5 \cdot 7 \%)$ & $373 / 7216(5 \cdot 2 \%)$ & $12 / 205(5 \cdot 9 \%)$ & 463/8783 (5·3\%) \\
\hline Vascular & $190 / 9022(2 \cdot 1 \%)$ & $57 / 1525(3 \cdot 7 \%)$ & $124 / 7216(1 \cdot 7 \%)$ & $15 / 205(7 \cdot 3 \%)$ & $175 / 8783(2 \cdot 0 \%)$ \\
\hline Head and neck & 326/9022 (3.6\%) & $56 / 1525(3 \cdot 7 \%)$ & $248 / 7216(3 \cdot 4 \%)$ & $11 / 205(5 \cdot 4 \%)$ & $312 / 8783(3 \cdot 6 \%)$ \\
\hline Plastics/Cutaneous & $469 / 9022(5 \cdot 2 \%)$ & $91 / 1525(6 \cdot 0 \%)$ & $358 / 7216(5 \cdot 0 \%)$ & $11 / 205(5 \cdot 4 \%)$ & $453 / 8783(5 \cdot 2 \%)$ \\
\hline Cardiac surgery & $54 / 9022(0 \cdot 6 \%)$ & $18 / 1525(1 \cdot 2 \%)$ & $34 / 7216(0 \cdot 5 \%)$ & $5 / 205(2 \cdot 4 \%)$ & 49/8783 (0.6\%) \\
\hline Thoracic (lung and other) & $113 / 9022(1 \cdot 3 \%)$ & $30 / 1525(2 \cdot 0 \%)$ & $82 / 7216(1 \cdot 1 \%)$ & $6 / 205(2 \cdot 9 \%)$ & $107 / 8783(1 \cdot 2 \%)$ \\
\hline Thoracic (gut) & $18 / 9022(0 \cdot 2 \%)$ & $6 / 1525(0 \cdot 4 \%)$ & $12 / 7216(0 \cdot 2 \%)$ & $2 / 205(1 \cdot 0 \%)$ & $16 / 8783(0 \cdot 2 \%)$ \\
\hline Neurosurgery & 186/9022 (2·1\%) & $66 / 1525(4 \cdot 3 \%)$ & 116/7216 (1·6\%) & $16 / 205(7 \cdot 8 \%)$ & 170/8783 (1.9\%) \\
\hline Other & 468/9022 (5·2\%) & $66 / 1525(4 \cdot 3 \%)$ & $399 / 7216(5 \cdot 5 \%)$ & $9 / 205(4 \cdot 4 \%)$ & 458/8783 (5·2\%) \\
\hline Surgical checklist & $5096 / 8730(58 \cdot 4 \%)$ & $815 / 1522(53 \cdot 5 \%)$ & 4281/7208 (59·4\%) & $124 / 205(60 \cdot 5 \%)$ & 5099/8771 (58·1\%) \\
\hline \multicolumn{6}{|l|}{ Preoperative comorbidity } \\
\hline Coronary artery disease & $154 / 9024(1 \cdot 7 \%)$ & 40/7218 (2·6\%) & 108/1525 (1·5\%) & $9 / 205(4 \cdot 4 \%)$ & $144 / 8785(1 \cdot 6 \%)$ \\
\hline Congestive heart failure & $76 / 9024(0 \cdot 8 \%)$ & $21 / 7218(1 \cdot 4 \%)$ & $52 / 1525(0 \cdot 7 \%)$ & $9 / 205(4 \cdot 4 \%)$ & $67 / 8785(0 \cdot 8 \%)$ \\
\hline Diabetes mellitus & $654 / 9024(7 \cdot 2 \%)$ & 168/7218 (11·0\%) & $466 / 1525(6 \cdot 5 \%)$ & $44 / 205(21 \cdot 5 \%)$ & 609/8785 (6.9\%) \\
\hline
\end{tabular}




\begin{tabular}{|c|c|c|c|c|c|}
\hline Cirrhosis & $7 / 9024(0 \cdot 1 \%)$ & $1 / 7218(0 \cdot 1 \%)$ & $5 / 1525(0 \cdot 1 \%)$ & $0 / 205(0 \%)$ & $7 / 8785(0 \cdot 1 \%)$ \\
\hline Metastatic cancer & 123/9024 (1·4\%) & $27 / 7218(1 \cdot 8 \%)$ & $91 / 1525(1 \cdot 3 \%)$ & $11 / 205(5 \cdot 4 \%)$ & 112/8785 (1·3\%) \\
\hline Hypertension & $1662 / 9024(18 \cdot 4 \%)$ & $319 / 7218(20 \cdot 9 \%)$ & $1279 / 1525(17 \cdot 7 \%)$ & $69 / 205(33 \cdot 7 \%)$ & $1586 / 8785(18 \cdot 1 \%)$ \\
\hline Stroke or Transient ischaemic attack & $80 / 9024(0 \cdot 9 \%)$ & 29/7218 (1.9\%) & $45 / 1525(0 \cdot 6 \%)$ & $6 / 205(2 \cdot 9 \%)$ & $74 / 8785(0 \cdot 8 \%)$ \\
\hline COPD/Asthma & $346 / 9024(3 \cdot 8 \%)$ & $67 / 7218(4 \cdot 4 \%)$ & $258 / 1525(3 \cdot 6 \%)$ & $13 / 205(6 \cdot 3 \%)$ & $331 / 8785(3 \cdot 8 \%)$ \\
\hline HIV positive/AIDS & $1211 / 9024(13 \cdot 4 \%)$ & 211/7218 (13·8\%) & $962 / 1525(13 \cdot 3 \%)$ & $17 / 205(8 \cdot 3 \%)$ & $1188 / 8785(13 \cdot 5 \%)$ \\
\hline Chronic renal disease & $150 / 9024(1 \cdot 7 \%)$ & $39 / 7218(2 \cdot 6 \%)$ & $97 / 1525(1 \cdot 3 \%)$ & $14 / 205(6 \cdot 8 \%)$ & $133 / 8785(1 \cdot 5 \%)$ \\
\hline
\end{tabular}

Data are mean (SD), median $\left(25^{\text {th }} / 75^{\text {th }}\right.$ percentile) or $\mathrm{n}$ (proportion). Denominators vary with the completeness of the data. Odds ratios were constructed for in-hospital

complications and mortality with univariate binary logistic regression analysis. The denominator for each group is shown. $\mathrm{CI}=\mathrm{confidence}$ interval. ASA=American Society

of Anesthesiologists. GIT= gastrointestinal. COPD=chronic obstructive pulmonary disease. HIV=human immunodeficiency virus. AIDS=acquired immunodeficiency

syndrome. 
Supplementary Table 6. Per-protocol representative sample of postoperative outcomes in the African Surgical Outcomes Study. Data presented as $\mathbf{n}(\%)$.

\begin{tabular}{|c|c|c|c|}
\hline Outcome & Number of patients & $\begin{array}{l}\text { Patients admitted to critical care } \\
\text { immediately after surgery }\end{array}$ & $\begin{array}{l}\text { Patients not admitted to critical care } \\
\text { immediately after surgery }\end{array}$ \\
\hline \multicolumn{4}{|l|}{ All surgeries } \\
\hline Mortality & $205 / 8990(2 \cdot 3)$ & $85 / 726(11 \cdot 7)$ & $120 / 8251(1 \cdot 5)$ \\
\hline Any complications & $1525 / 8797(17 \cdot 3)$ & $326 / 706(46 \cdot 2)$ & $1196 / 8025(14 \cdot 9)$ \\
\hline Critical care admission to treat complications & $244 / 1523(16 \cdot 0)$ & $190 / 326 *(58 \cdot 3)$ & $53 / 1196 \dagger(4 \cdot 4)$ \\
\hline Death following a postoperative complication & $156 / 1525(10 \cdot 2)$ & $74 / 326 *(22 \cdot 7)$ & $82 / 1196 \dagger(6 \cdot 9)$ \\
\hline \multicolumn{4}{|l|}{ Elective surgery only } \\
\hline Mortality & $42 / 3846(1 \cdot 1)$ & $9 / 241(3 \cdot 7)$ & $33 / 3605(0 \cdot 9)$ \\
\hline Complications & $467 / 3734(12 \cdot 5)$ & $91 / 238(38 \cdot 2)$ & $376 / 3496(10 \cdot 8)$ \\
\hline Critical care admission to treat complications & $91 / 467(19 \cdot 5)$ & $50 / 91 *(54 \cdot 9)$ & $14 / 376 \dagger(3 \cdot 7)$ \\
\hline Death following a postoperative complication & $26 / 467(5 \cdot 6)$ & $8 / 91 *(8 \cdot 8)$ & $18 / 376 \dagger(4 \cdot 8)$ \\
\hline
\end{tabular}

Denominators vary with the completeness of the data. *total number admitted to critical care immediately following surgery; $\uparrow$ total number not admitted to critical care immediately after surgery 
Supplementary Table 7. Postoperative complications (per-protocol, representative sample analysis) in the African Surgical Outcomes

\section{Study (ASOS). Data are presented as n (\%).}

\begin{tabular}{|c|c|c|c|c|c|c|}
\hline Complications & $\begin{array}{c}\text { Number } \\
\text { of } \\
\text { patients }\end{array}$ & Mild & Moderate & Severe & $\begin{array}{c}\text { Mortality for all patients } \\
\text { that developed } \\
\text { complications }\end{array}$ & $\begin{array}{c}\text { Mortality for elective } \\
\text { surgical patients that } \\
\text { developed complications }\end{array}$ \\
\hline \multicolumn{7}{|l|}{ Infectious complications } \\
\hline Superficial surgical site & 8796 & $287(3.2)$ & $240(2.7)$ & $60(0.7)$ & $29 / 687(4.22)$ & $5 / 182(2.7)$ \\
\hline Deep surgical site & 8798 & $56(0.6)$ & $107(1.2)$ & $90(1.0)$ & $35 / 253(13.8)$ & $3 / 55(5.5)$ \\
\hline Body cavity & 8797 & $22(0.2)$ & $48(0.5)$ & $43(0.5)$ & $23 / 113(20.4)$ & $1 / 19(5.3)$ \\
\hline Pneumonia & 8797 & $34(0.4)$ & $69(0.8)$ & $42(0.5)$ & $36 / 185$ (24.8) & $5 / 34(14.7)$ \\
\hline Urinary tract & 8797 & $49(0.5)$ & $23(0.3)$ & $17(0.2)$ & $17 / 112(19.1)$ & $2 / 29(6.9)$ \\
\hline Bloodstream & 8797 & $19(0.2)$ & $39(0.4)$ & $52(0.6)$ & $44 / 110(40.0)$ & $5 / 18(27.8)$ \\
\hline \multicolumn{5}{|c|}{ Total number of patients with infectious complications } & 89/891 (10.0) & $11 / 267(4.1)$ \\
\hline \multicolumn{7}{|c|}{ Cardiovascular complications } \\
\hline Myocardial infarction & 8797 & $7(0.1)$ & $1(0.0)$ & $3(0.0)$ & $3 / 11(27.3)$ & $0 / 2(0.0)$ \\
\hline Arrhythmia & 8797 & $10(0.1)$ & $13(0.1)$ & $10(0.1)$ & $10 / 33(30.3)$ & $1 / 10(10.0)$ \\
\hline Pulmonary oedema & 8797 & $14(0.2)$ & $12(0.1)$ & $8(0.1)$ & $16 / 34(47.1)$ & $1 / 5(20.0)$ \\
\hline Pulmonary embolism & 8797 & $2(0.0)$ & $1(0.0)$ & $10(0.1)$ & $11 / 13(84.6)$ & $5 / 6(83.3)$ \\
\hline Stroke & 8756 & $5(0.1)$ & $6(0.1)$ & $6(0.1)$ & $5 / 17(29.4)$ & $1 / 6(16.7)$ \\
\hline Cardiac arrest & 8779 & & & $97(1.1)$ & $87 / 97(89.7)$ & $12 / 17(70.6)$ \\
\hline \multicolumn{5}{|c|}{ Total number of patients with cardiovascular complications } & 95/163 (58.3) & 14/41 (34.1) \\
\hline \multicolumn{7}{|l|}{ Other complications } \\
\hline Gastrointestinal bleed & 8797 & $18(0.2)$ & $7(0.1)$ & $7(0.1)$ & $12 / 32(37.5)$ & $1 / 7(14.3)$ \\
\hline Acute kidney injury & 8797 & $34(0.4)$ & $39(0.4)$ & $37(0.4)$ & $43 / 110(39.1)$ & $4 / 15(26.7)$ \\
\hline Postoperative bleed & 8797 & $82(0.9)$ & 297 (3.5) & $46(0.5)$ & $32 / 425(7.5)$ & 4/112 (3.6) \\
\hline ARDS & 8797 & $10(0.1)$ & $16(0.2)$ & $14(0.2)$ & $20 / 40(50.0)$ & 3/7 (42.9) \\
\hline Anastomotic leak & 8795 & $7(0.1)$ & $7(0.1)$ & $20(0.2)$ & $13 / 34(38.2)$ & $3 / 11(27.3)$ \\
\hline All others & 8791 & $118(1.3)$ & $111(1.2)$ & $72(0.8)$ & $34 / 301(11.3)$ & $5 / 100(5.0)$ \\
\hline \multicolumn{5}{|c|}{ Total number of patients with other complications } & $91 / 794(11.5)$ & $12 / 232(5.2)$ \\
\hline \multicolumn{5}{|c|}{ Total number of patients with complications } & $156 / 1525(10.2)$ & $26 / 468$ (5.6) \\
\hline
\end{tabular}

Denominators vary with the completeness of the data. ARDS acute respiratory distress syndrome 
Supplementary Table 8. The association between the primary indication for surgery and postoperative complications and in-hospital mortality, per-protocol analysis. Data presented as n (\%)

\begin{tabular}{|c|c|c|c|c|c|c|c|c|c|}
\hline & $\begin{array}{l}\text { All patients } \\
(\mathrm{n}=\mathbf{8 9 8 2})\end{array}$ & $\begin{array}{c}\text { Complications } \\
(\mathrm{n}=1521)\end{array}$ & $\begin{array}{c}\text { No complications } \\
(n=7196)\end{array}$ & $\begin{array}{c}\text { Odds ratio }(95 \% \\
\text { CI) }\end{array}$ & $P$ value & $\begin{array}{c}\text { Died } \\
(n=205)\end{array}$ & $\begin{array}{l}\text { Survived } \\
(\mathrm{n}=8744)\end{array}$ & $\begin{array}{c}\text { Odds ratio (95\% } \\
\text { CI) }\end{array}$ & $\begin{array}{c}\mathbf{P} \\
\text { value }\end{array}$ \\
\hline $\begin{array}{l}\text { Non-communicable } \\
\text { disease }\end{array}$ & $3709(41 \cdot 1 \%)$ & $555(36 \cdot 5 \%)$ & $3048(42 \cdot 4 \%)$ & Reference & & $80(39 \cdot 0 \%)$ & $\begin{array}{c}3616 \\
(41 \cdot 4 \%)\end{array}$ & Reference & \\
\hline Infective & $1203(13 \cdot 3 \%)$ & $334(22 \cdot 0 \%)$ & $824(11 \cdot 5 \%)$ & $2 \cdot 23(1 \cdot 90-2 \cdot 60)$ & $<0 \cdot 0001$ & $56(27 \cdot 3 \%)$ & $\begin{array}{c}1138 \\
(13 \cdot 0 \%)\end{array}$ & $2 \cdot 22(1 \cdot 57-3 \cdot 15)$ & $<0 \cdot 0001$ \\
\hline Trauma & $1631(18 \cdot 1 \%)$ & $299(19 \cdot 7 \%)$ & $1250(17 \cdot 4 \%)$ & $1 \cdot 31(1 \cdot 13-1 \cdot 53)$ & $0 \cdot 0006$ & $54(26 \cdot 3 \%)$ & $\begin{array}{c}1570 \\
(18 \cdot 0 \%) \\
\end{array}$ & $1 \cdot 56(1 \cdot 10-2 \cdot 21)$ & $0 \cdot 01$ \\
\hline Caesarean section & $2439(27 \cdot 0 \%)$ & $333(21 \cdot 9 \%)$ & $2074(28 \cdot 8 \%)$ & $0 \cdot 88(0 \cdot 76-1 \cdot 02)$ & 0.09 & $15(7 \cdot 3 \%)$ & $\begin{array}{c}2420 \\
(27 \cdot 7 \%)\end{array}$ & $0 \cdot 28(0 \cdot 16-0 \cdot 49)$ & $<0 \cdot 0001$ \\
\hline
\end{tabular}


Supplementary Table 9. The African regional level-specific reported mortality, postoperative complications, critical care admission and duration of hospital stay

\begin{tabular}{|c|c|c|c|c|c|c|c|c|}
\hline Hospital & Patients & $\begin{array}{l}\text { In-hospital } \\
\text { mortality }\end{array}$ & $\begin{array}{c}\text { \% In-hospital mortality } \\
(\mathbf{9 5 \%} \mathrm{CI})\end{array}$ & $\begin{array}{l}\text { Postoperative } \\
\text { complications }\end{array}$ & $\begin{array}{c}\text { \% Postoperative } \\
\text { complications ( } 95 \% \mathrm{CI})\end{array}$ & $\begin{array}{l}\text { Critical care } \\
\text { admission }\end{array}$ & $\begin{array}{c}\% \text { Critical care } \\
\text { admission }(95 \% \mathrm{CI})\end{array}$ & $\begin{array}{l}\text { Median days in } \\
\text { hospital }\left(25^{\text {th }} / 75^{\text {th }}\right. \\
\text { centile })\end{array}$ \\
\hline Central Africa & $\begin{array}{c}541 \\
(4 \cdot 7 \%)\end{array}$ & $15 / 541$ & $2 \cdot 8 \%(1 \cdot 4-4 \cdot 2)$ & $93 / 538$ & $17 \cdot 3 \%(14 \cdot 1-20 \cdot 5)$ & $19 / 541$ & $3 \cdot 5 \%(2 \cdot 0-5 \cdot 1)$ & $5(3-10)$ \\
\hline Eastern Africa & $\begin{array}{c}1420 \\
(12 \cdot 4 \%)\end{array}$ & $19 / 1361$ & $1 \cdot 4 \%(0 \cdot 8-2 \cdot 1)$ & $361 / 1340$ & $26 \cdot 9 \%(24 \cdot 6-29 \cdot 3)$ & $45 / 1363$ & $3 \cdot 3 \%(2 \cdot 4-4 \cdot 3)$ & $3(3-5)$ \\
\hline Northern Africa & $\begin{array}{c}861 \\
(7 \cdot 5 \%) \\
\end{array}$ & $12 / 857$ & $1 \cdot 4 \%(0 \cdot 6-2 \cdot 2)$ & $192 / 856$ & $22 \cdot 4 \%(19 \cdot 6-25 \cdot 2)$ & $50 / 857$ & $5 \cdot 8 \%(4 \cdot 3-7 \cdot 4)$ & $2(1-4)$ \\
\hline Southern Africa & $\begin{array}{c}6527 \\
(57 \cdot 1 \%)\end{array}$ & $154 / 6491$ & $2 \cdot 4 \%(2 \cdot 0-2 \cdot 7)$ & $953 / 6266$ & $15 \cdot 2 \%(14 \cdot 3-16 \cdot 1)$ & 261/6307 & $4 \cdot 1 \%(3 \cdot 6-4 \cdot 6)$ & $3(2-5)$ \\
\hline Western Africa & $\begin{array}{c}1463 \\
(12 \cdot 8 \%)\end{array}$ & $29 / 1333$ & $2 \cdot 2 \%(1 \cdot 4-3 \cdot 0)$ & $284 / 1276$ & $22 \cdot 3 \%(20 \cdot 0-24 \cdot 5)$ & $102 / 1313$ & $7 \cdot 8 \%(6 \cdot 3-9 \cdot 2)$ & $5(3-7)$ \\
\hline Indian Ocean Islands & $\begin{array}{c}610 \\
(5 \cdot 3 \%)\end{array}$ & $10 / 610$ & $1 \cdot 6 \%(0 \cdot 6-2 \cdot 6)$ & $94 / 609$ & $15 \cdot 4 \%(12 \cdot 6-18 \cdot 3)$ & $34 / 610$ & $5 \cdot 6 \%(3 \cdot 8-7 \cdot 4)$ & $3(2-6)$ \\
\hline
\end{tabular}

Denominators vary with the completeness of the data. CI confidence interval 
Supplementary Table 10. The hospital level-specific reported mortality, postoperative complications, critical care admission and duration of hospital stay

\begin{tabular}{|c|c|c|c|c|c|c|c|c|}
\hline Hospital & Patients & $\begin{array}{c}\text { In-hospital } \\
\text { mortality }\end{array}$ & $\begin{array}{c}\text { \% In-hospital mortality } \\
(95 \% \mathrm{CI})\end{array}$ & $\begin{array}{l}\text { Postoperative } \\
\text { complications }\end{array}$ & $\begin{array}{c}\% \text { Postoperative } \\
\text { complications }(95 \% \mathrm{CI})\end{array}$ & $\begin{array}{c}\text { Critical care } \\
\text { admission }\end{array}$ & $\begin{array}{c}\% \text { Critical care } \\
\text { admission }(95 \% \mathrm{CI})\end{array}$ & $\begin{array}{c}\text { Median days in hospital } \\
\left(25^{\text {th }} / 75^{\text {th }} \text { centile }\right)\end{array}$ \\
\hline Primary-level & $971(8 \cdot 9 \%)$ & $10 / 947$ & $1 \cdot 1 \%(0 \cdot 4-1 \cdot 7)$ & $161 / 944$ & $17 \cdot 1 \%(14 \cdot 7-19 \cdot 5)$ & $37 / 948$ & $3 \cdot 9 \%(2 \cdot 7-5 \cdot 1)$ & $3(2-5)$ \\
\hline Secondary-level & $3433(31 \cdot 4 \%)$ & $61 / 3337$ & $1 \cdot 8 \%(1 \cdot 4-2 \cdot 3)$ & $518 / 3298$ & $15 \cdot 7 \%(14 \cdot 5-16 \cdot 9)$ & $93 / 3328$ & $2 \cdot 8 \%(2 \cdot 2-3 \cdot 4)$ & $3(2-5)$ \\
\hline Tertiary-level & $6535(59 \cdot 7 \%)$ & $161 / 6469$ & $2 \cdot 5 \%(2 \cdot 1-2 \cdot 9)$ & $1192 / 6203$ & $19 \cdot 2 \%(18 \cdot 2-20 \cdot 2)$ & $315 / 6269$ & $5 \cdot 0 \%(4 \cdot 5-5 \cdot 6)$ & $3(2-6)$ \\
\hline All & 10939 & $232 / 10753$ & $2 \cdot 2 \%(1 \cdot 9-2 \cdot 4)$ & $1871 / 10445$ & $17 \cdot 9 \%(17 \cdot 1-18 \cdot 6)$ & $445 / 10545$ & $4 \cdot 2 \%(3 \cdot 8-4 \cdot 6)$ & $3(2-6)$ \\
\hline
\end{tabular}

Denominators vary with the completeness of the data. CI confidence interval; IQR interquartile range 
Supplementary Table 11. Multivariable model of in-hospital mortality using a per-protocol analysis of DCP3 hospital category

\section{compliant data.}

\begin{tabular}{|c|c|c|c|}
\hline & Odds ratio (OR) & 95\% confidence interval (CI) & P-value \\
\hline Intercept & $0 \cdot 002$ & $0 \cdot 000-0 \cdot 049$ & $0 \cdot 0001$ \\
\hline \multicolumn{4}{|l|}{ Patient factors } \\
\hline Age spline 1 & $0 \cdot 988$ & $0 \cdot 864-1 \cdot 130$ & $0 \cdot 86$ \\
\hline Age spline 2 & $1 \cdot 111$ & $0 \cdot 125-9 \cdot 900$ & $0 \cdot 93$ \\
\hline Age spline 3 & $1 \cdot 062$ & $0 \cdot 005-228 \cdot 722$ & $0 \cdot 98$ \\
\hline Age spline 4 & $0 \cdot 702$ & $0 \cdot 014-34 \cdot 248$ & $0 \cdot 86$ \\
\hline ASA 1 & Reference & & \\
\hline ASA 2 & $1 \cdot 529$ & $0 \cdot 955-2 \cdot 447$ & $0 \cdot 08$ \\
\hline ASA 3 & $3 \cdot 690$ & $2 \cdot 277-5 \cdot 981$ & $<0 \cdot 0001$ \\
\hline ASA 4 or 5 & $10 \cdot 121$ & $5 \cdot 872-17 \cdot 446$ & $<0 \cdot 0001$ \\
\hline \multicolumn{4}{|l|}{ Surgical factors } \\
\hline Elective surgery & Reference & & \\
\hline Urgent surgery & $3 \cdot 512$ & $2 \cdot 278-5 \cdot 416$ & $<0 \cdot 0001$ \\
\hline Emergent surgery & $4 \cdot 638$ & $2 \cdot 992-7 \cdot 191$ & $<0 \cdot 0001$ \\
\hline Minor surgery & Reference & & \\
\hline Intermediate surgery & $1 \cdot 620$ & $0 \cdot 987-2 \cdot 660$ & $0 \cdot 06$ \\
\hline Major surgery & $2 \cdot 444$ & $1 \cdot 441-4 \cdot 146$ & $0 \cdot 0009$ \\
\hline Cardiothoracic and vascular surgery & $1 \cdot 833$ & $1 \cdot 011-3 \cdot 324$ & $0 \cdot 05$ \\
\hline Ear nose and throat & $2 \cdot 381$ & $1 \cdot 103-5 \cdot 137$ & $0 \cdot 03$ \\
\hline Gastrointestinal and hepatobiliary & $2 \cdot 686$ & $1 \cdot 609-4 \cdot 482$ & $0 \cdot 0002$ \\
\hline Gynaecology and obstetrics & $0 \cdot 337$ & $0 \cdot 172-0 \cdot 660$ & $0 \cdot 0015$ \\
\hline Neurosurgery & $3 \cdot 028$ & $1 \cdot 481-6 \cdot 191$ & $0 \cdot 0024$ \\
\hline Other & $1 \cdot 158$ & $0 \cdot 517-2 \cdot 593$ & $0 \cdot 72$ \\
\hline Plastics and breast & $1 \cdot 377$ & $0 \cdot 649-2 \cdot 921$ & $0 \cdot 41$ \\
\hline Urology & $1 \cdot 771$ & $0 \cdot 839-3 \cdot 738$ & $0 \cdot 13$ \\
\hline
\end{tabular}




\begin{tabular}{|c|c|c|c|}
\hline \multicolumn{4}{|c|}{ Countries } \\
\hline A & $2 \cdot 025$ & $1 \cdot 036-3 \cdot 960$ & $0 \cdot 04$ \\
\hline B & $1 \cdot 098$ & $0 \cdot 305-3 \cdot 962$ & $0 \cdot 89$ \\
\hline $\mathrm{C}$ & $0 \cdot 190$ & $0 \cdot 025-1 \cdot 433$ & $0 \cdot 11$ \\
\hline $\mathrm{D}$ & 1.903 & $0 \cdot 955-3 \cdot 791$ & 0.07 \\
\hline$E$ & $1 \cdot 060$ & $0 \cdot 489-2 \cdot 295$ & $0 \cdot 88$ \\
\hline F & $2 \cdot 523$ & $1 \cdot 288-4 \cdot 942$ & $0 \cdot 0070$ \\
\hline G & N/A & & \\
\hline $\mathrm{H}$ & $0 \cdot 682$ & $0 \cdot 314-1 \cdot 483$ & $0 \cdot 33$ \\
\hline I & $0 \cdot 831$ & $0 \cdot 365-1 \cdot 893$ & $0 \cdot 66$ \\
\hline $\mathrm{J}$ & 0.623 & $0 \cdot 273-1 \cdot 419$ & $0 \cdot 26$ \\
\hline
\end{tabular}

DCP3 Disease Control Priorities in Developing Countries classification; ASA American Society of Anesthesiologists; A-J anonymised countries; N/A not applicable as no outcome reported 
Supplementary Table 12. Multivariable logistic regression with multiple imputation for missing data

\begin{tabular}{|c|c|c|c|}
\hline & $\begin{array}{c}\text { Main analysis odds ratio without } \\
\text { imputation for missing data }\end{array}$ & $\begin{array}{c}\text { Minimum odds ratio obtained with multiple } \\
\text { imputation for missing data }\end{array}$ & $\begin{array}{c}\text { Maximum odds ratio obtained with multiple } \\
\text { imputation for missing data }\end{array}$ \\
\hline Intercept & $0 \cdot 002$ & $0 \cdot 002$ & $0 \cdot 002$ \\
\hline \multicolumn{4}{|l|}{ Patient factors } \\
\hline Age spline 1 & $0 \cdot 990$ & 0.990 & 0.991 \\
\hline Age spline 2 & $1 \cdot 125$ & $1 \cdot 114$ & $1 \cdot 141$ \\
\hline Age spline 3 & $0 \cdot 985$ & $0 \cdot 951$ & $1 \cdot 008$ \\
\hline Age spline 4 & 0.773 & 0.763 & $0 \cdot 795$ \\
\hline ASA 1 & Reference & Reference & Reference \\
\hline ASA 2 & $1 \cdot 438$ & $1 \cdot 422$ & $1 \cdot 438$ \\
\hline ASA 3 & $3 \cdot 627$ & $3 \cdot 584$ & $3 \cdot 621$ \\
\hline ASA 4 or 5 & $10 \cdot 153$ & $10 \cdot 061$ & $10 \cdot 158$ \\
\hline \multicolumn{4}{|l|}{ Surgical factors } \\
\hline Elective surgery & Reference & Reference & Reference \\
\hline Urgent surgery & $3 \cdot 296$ & $3 \cdot 289$ & $3 \cdot 306$ \\
\hline Emergent surgery & $4 \cdot 397$ & $4 \cdot 379$ & $4 \cdot 403$ \\
\hline Minor surgery & Reference & Reference & Reference \\
\hline Intermediate surgery & $1 \cdot 699$ & 1.696 & $1 \cdot 704$ \\
\hline Major surgery & $2 \cdot 595$ & $2 \cdot 591$ & $2 \cdot 606$ \\
\hline $\begin{array}{l}\text { Cardiothoracic and } \\
\text { vascular surgery }\end{array}$ & $1 \cdot 773$ & $1 \cdot 782$ & $1 \cdot 791$ \\
\hline Ear nose and throat & $2 \cdot 279$ & $2 \cdot 290$ & $2 \cdot 298$ \\
\hline $\begin{array}{l}\text { Gastrointestinal and } \\
\text { hepatobiliary }\end{array}$ & $2 \cdot 599$ & $2 \cdot 607$ & $2 \cdot 619$ \\
\hline $\begin{array}{l}\text { Gynaecology and } \\
\text { obstetrics }\end{array}$ & $0 \cdot 329$ & $0 \cdot 329$ & $0 \cdot 331$ \\
\hline Neurosurgery & $2 \cdot 794$ & $2 \cdot 803$ & $2 \cdot 819$ \\
\hline Other & $1 \cdot 133$ & $1 \cdot 134$ & $1 \cdot 150$ \\
\hline Plastics and breast & $1 \cdot 576$ & 1.579 & $1 \cdot 588$ \\
\hline
\end{tabular}




\begin{tabular}{|c|c|c|c|}
\hline Urology & $1 \cdot 684$ & 1.673 & $1 \cdot 697$ \\
\hline \multicolumn{4}{|c|}{ Countries } \\
\hline $\mathrm{A}$ & 2.006 & 1.993 & $2 \cdot 018$ \\
\hline B & $1 \cdot 080$ & $1 \cdot 080$ & $1 \cdot 085$ \\
\hline $\mathrm{C}$ & $0 \cdot 387$ & $0 \cdot 384$ & $0 \cdot 387$ \\
\hline $\mathrm{D}$ & $1 \cdot 892$ & 1.855 & $1 \cdot 892$ \\
\hline $\mathrm{E}$ & $1 \cdot 062$ & $1 \cdot 063$ & $1 \cdot 065$ \\
\hline F & $2 \cdot 525$ & $2 \cdot 525$ & $2 \cdot 530$ \\
\hline G & 0.407 & $0 \cdot 407$ & $0 \cdot 408$ \\
\hline $\mathrm{H}$ & 0.667 & 0.666 & 0.668 \\
\hline I & $0 \cdot 821$ & $0 \cdot 809$ & $0 \cdot 822$ \\
\hline $\mathrm{J}$ & 0.614 & $0 \cdot 611$ & $0 \cdot 615$ \\
\hline
\end{tabular}

ASA American Society of Anesthesiologists; A-J anonymised countries; N/A not applicable as no outcome reported 
Supplementary Table 13. Multivariable model of in-hospital mortality per-protocol analysis of DCP3 hospital category compliant data, with DCP3 hospital categories forced into multivariable analysis.

\begin{tabular}{|c|c|c|c|}
\hline & Odds ratio (OR) & $95 \%$ confidence interval (CI) & P-value \\
\hline Intercept & $0 \cdot 001$ & $0 \cdot 000-0 \cdot 026$ & $<0 \cdot 0001$ \\
\hline \multicolumn{4}{|l|}{ Patient factors } \\
\hline Age spline 1 & $0 \cdot 984$ & $0 \cdot 861-1 \cdot 126$ & $0 \cdot 82$ \\
\hline Age spline 2 & $1 \cdot 182$ & $0 \cdot 132-10 \cdot 582$ & $0 \cdot 88$ \\
\hline Age spline 3 & $0 \cdot 923$ & $0 \cdot 004-200 \cdot 849$ & $0 \cdot 98$ \\
\hline Age spline 4 & $0 \cdot 768$ & $0 \cdot 016-37 \cdot 733$ & $0 \cdot 89$ \\
\hline ASA 1 & Reference & & \\
\hline ASA 2 & $1 \cdot 521$ & $0 \cdot 950-2 \cdot 435$ & $0 \cdot 08$ \\
\hline ASA 3 & $3 \cdot 598$ & $2 \cdot 220-5 \cdot 832$ & $<0 \cdot 0001$ \\
\hline ASA 4 or 5 & $10 \cdot 205$ & $5 \cdot 913-17 \cdot 614$ & $<0 \cdot 0001$ \\
\hline \multicolumn{4}{|l|}{ Surgical factors } \\
\hline Elective surgery & Reference & & \\
\hline Urgent surgery & $3 \cdot 568$ & $2 \cdot 314-5 \cdot 500$ & $<0 \cdot 0001$ \\
\hline Emergent surgery & $4 \cdot 779$ & $3 \cdot 078-7 \cdot 420$ & $<0 \cdot 0001$ \\
\hline Minor surgery & Reference & & \\
\hline Intermediate surgery & $1 \cdot 599$ & $0 \cdot 973-2 \cdot 626$ & $0 \cdot 06$ \\
\hline Major surgery & $2 \cdot 373$ & $1 \cdot 398-4 \cdot 029$ & $0 \cdot 0014$ \\
\hline Cardiothoracic and vascular surgery & $1 \cdot 752$ & $0 \cdot 964-3 \cdot 185$ & $0 \cdot 07$ \\
\hline Ear nose and throat & $2 \cdot 192$ & $1 \cdot 013-4 \cdot 746$ & $0 \cdot 05$ \\
\hline Gastrointestinal and hepatobiliary & $2 \cdot 693$ & $1 \cdot 612-4 \cdot 500$ & $0 \cdot 0002$ \\
\hline Gynaecology and obstetrics & $0 \cdot 346$ & $0 \cdot 176-0 \cdot 681$ & $0 \cdot 0021$ \\
\hline Neurosurgery & $2 \cdot 682$ & $1 \cdot 302-5 \cdot 525$ & $0 \cdot 0074$ \\
\hline Other & $1 \cdot 118$ & $0 \cdot 498-2 \cdot 508$ & $0 \cdot 79$ \\
\hline Plastics and breast & $1 \cdot 443$ & $0 \cdot 679-3 \cdot 067$ & $0 \cdot 34$ \\
\hline Urology & $1 \cdot 696$ & $0 \cdot 803-3 \cdot 585$ & $0 \cdot 17$ \\
\hline
\end{tabular}




\begin{tabular}{|c|c|c|c|}
\hline \multicolumn{4}{|l|}{ Countries } \\
\hline A & $2 \cdot 194$ & $1 \cdot 122-4 \cdot 288$ & $0 \cdot 022$ \\
\hline B & $1 \cdot 055$ & $0 \cdot 290-3 \cdot 833$ & $0 \cdot 93$ \\
\hline $\mathrm{C}$ & $0 \cdot 185$ & $0 \cdot 024-1 \cdot 400$ & $0 \cdot 10$ \\
\hline $\mathrm{D}$ & $2 \cdot 237$ & $1 \cdot 111-4 \cdot 507$ & $0 \cdot 024$ \\
\hline $\mathrm{E}$ & $1 \cdot 091$ & $0 \cdot 503-2 \cdot 366$ & $0 \cdot 83$ \\
\hline $\mathrm{F}$ & $2 \cdot 660$ & $1 \cdot 348-5 \cdot 251$ & $0 \cdot 0048$ \\
\hline G & $\mathrm{N} / \mathrm{A}$ & & \\
\hline $\mathrm{H}$ & $0 \cdot 619$ & $0 \cdot 284-1 \cdot 352$ & $0 \cdot 23$ \\
\hline I & $0 \cdot 897$ & $0 \cdot 393-2 \cdot 044$ & $0 \cdot 80$ \\
\hline $\mathrm{J}$ & 0.573 & $0 \cdot 251-1 \cdot 312$ & $0 \cdot 19$ \\
\hline Increasing hospital facility level & $1 \cdot 364$ & $1 \cdot 039-1 \cdot 789$ & $0 \cdot 0252$ \\
\hline
\end{tabular}

DCP3 Disease Control Priorities in Developing Countries classification; ASA American Society of Anesthesiologists; A-J anonymised countries; N/A not applicable as no outcome reported 
Supplementary Table 14. Multivariable model of in-hospital mortality per-protocol analysis and DCP3 hospital category compliant,

with university affiliation forced into multivariable analysis.

\begin{tabular}{|c|c|c|c|}
\hline & Odds ratio (OR) & 95\% confidence interval (CI) & P-value \\
\hline Intercept & $0 \cdot 004$ & $0 \cdot 000-0 \cdot 101$ & $0 \cdot 0008$ \\
\hline \multicolumn{4}{|l|}{ Patient factors } \\
\hline Age spline 1 & $0 \cdot 973$ & $0 \cdot 850-1 \cdot 113$ & $0 \cdot 69$ \\
\hline Age spline 2 & $1 \cdot 495$ & $0 \cdot 164-13 \cdot 597$ & $0 \cdot 72$ \\
\hline Age spline 3 & $0 \cdot 487$ & $0 \cdot 002-110 \cdot 182$ & $0 \cdot 80$ \\
\hline Age spline 4 & $1 \cdot 298$ & $0 \cdot 026-65 \cdot 569$ & $0 \cdot 90$ \\
\hline ASA 1 & Reference & & \\
\hline ASA 2 & $1 \cdot 496$ & $0 \cdot 931-2 \cdot 402$ & $0 \cdot 10$ \\
\hline ASA 3 & $3 \cdot 585$ & $2 \cdot 201-5 \cdot 838$ & $<0 \cdot 0001$ \\
\hline ASA 4 or 5 & $9 \cdot 702$ & $5 \cdot 594-16 \cdot 825$ & $<0 \cdot 0001$ \\
\hline \multicolumn{4}{|l|}{ Surgical factors } \\
\hline Elective surgery & Reference & & \\
\hline Urgent surgery & $3 \cdot 545$ & $2 \cdot 292-5 \cdot 481$ & $<0.0001$ \\
\hline Emergent surgery & $4 \cdot 594$ & $2 \cdot 942-7 \cdot 173$ & $<0 \cdot 0001$ \\
\hline Minor surgery & Reference & & \\
\hline Intermediate surgery & $1 \cdot 613$ & $0 \cdot 981-2 \cdot 650$ & $0 \cdot 06$ \\
\hline Major surgery & $2 \cdot 440$ & $1 \cdot 435-4 \cdot 150$ & $0 \cdot 0010$ \\
\hline Cardiothoracic and vascular surgery & $1 \cdot 919$ & $1 \cdot 050-3 \cdot 506$ & $0 \cdot 03$ \\
\hline Ear nose and throat & $2 \cdot 430$ & $1 \cdot 118-5 \cdot 280$ & 0.03 \\
\hline Gastrointestinal and hepatobiliary & $2 \cdot 756$ & $1 \cdot 638-4 \cdot 639$ & $0 \cdot 0001$ \\
\hline Gynaecology and obstetrics & $0 \cdot 314$ & $0 \cdot 157-0 \cdot 630$ & $0 \cdot 0011$ \\
\hline Neurosurgery & $3 \cdot 159$ & $1 \cdot 533-6 \cdot 508$ & $0 \cdot 0018$ \\
\hline Other & $1 \cdot 188$ & $0 \cdot 529-2 \cdot 669$ & $0 \cdot 68$ \\
\hline Plastics and breast & $1 \cdot 459$ & $0 \cdot 684-3 \cdot 112$ & $0 \cdot 33$ \\
\hline Urology & $1 \cdot 872$ & $0 \cdot 883-3 \cdot 967$ & $0 \cdot 10$ \\
\hline
\end{tabular}




\begin{tabular}{|c|c|c|c|}
\hline \multicolumn{4}{|l|}{ Countries } \\
\hline A & $2 \cdot 257$ & $1 \cdot 117-4 \cdot 562$ & $0 \cdot 0234$ \\
\hline B & $1 \cdot 132$ & $0 \cdot 312-4 \cdot 113$ & $0 \cdot 85$ \\
\hline $\mathrm{C}$ & $0 \cdot 184$ & $0 \cdot 024-1 \cdot 392$ & $0 \cdot 10$ \\
\hline $\mathrm{D}$ & $2 \cdot 037$ & $1 \cdot 006-4 \cdot 123$ & $0 \cdot 0481$ \\
\hline$E$ & $1 \cdot 303$ & $0 \cdot 546-3 \cdot 111$ & $0 \cdot 55$ \\
\hline $\mathrm{F}$ & $2 \cdot 520$ & $1 \cdot 286-4 \cdot 941$ & $0 \cdot 0071$ \\
\hline G & N/A & & \\
\hline $\mathrm{H}$ & $0 \cdot 434$ & $0 \cdot 150-1 \cdot 255$ & $0 \cdot 12$ \\
\hline I & $0 \cdot 865$ & $0 \cdot 379-1 \cdot 975$ & $0 \cdot 73$ \\
\hline $\mathrm{J}$ & $0 \cdot 693$ & $0 \cdot 299-1 \cdot 608$ & $0 \cdot 39$ \\
\hline University-affiliation & $0 \cdot 791$ & $0 \cdot 499-1 \cdot 255$ & $0 \cdot 32$ \\
\hline
\end{tabular}

DCP3 Disease Control Priorities in Developing Countries; ASA American Society of Anesthesiologists; A-J anonymised countries; N/A not applicable as no outcome reported 
Figure 1. Participating countries in the African Surgical Outcomes Study

\section{Figure 2. African Surgical Outcomes Study (ASOS) country, hospital and patient recruitment}

Footnote: Representative hospitals provided data on the number of eligible patients for the study, and recruited $>90 \%$ of the eligible patients into the study

Figure 3. Surgical mortality following elective surgery in high-income, low-middle income, and African countries

Footnote: ISOS International Surgical Outcomes Study, ASOS African Surgical Outcomes Study, HIC high income countries, LMIC low-middle income countries

Supplementary Figure 1. Per-protocol calibration plot for the in-hospital mortality multivariable model

Supplementary Figure 2. Per-protocol sample analysis of surgical mortality following elective surgery in high-income, low-middle income, and African countries

Footnote: ISOS International Surgical Outcomes Study, ASOS African Surgical Outcomes Study, HIC high income countries, LMIC low-middle income countries

Supplementary Figure 3. African regional participation of countries in the African Surgical Outcomes Study

Footnote: Regions include central, eastern, northern, southern, western Africa, and Indian Ocean Islands 


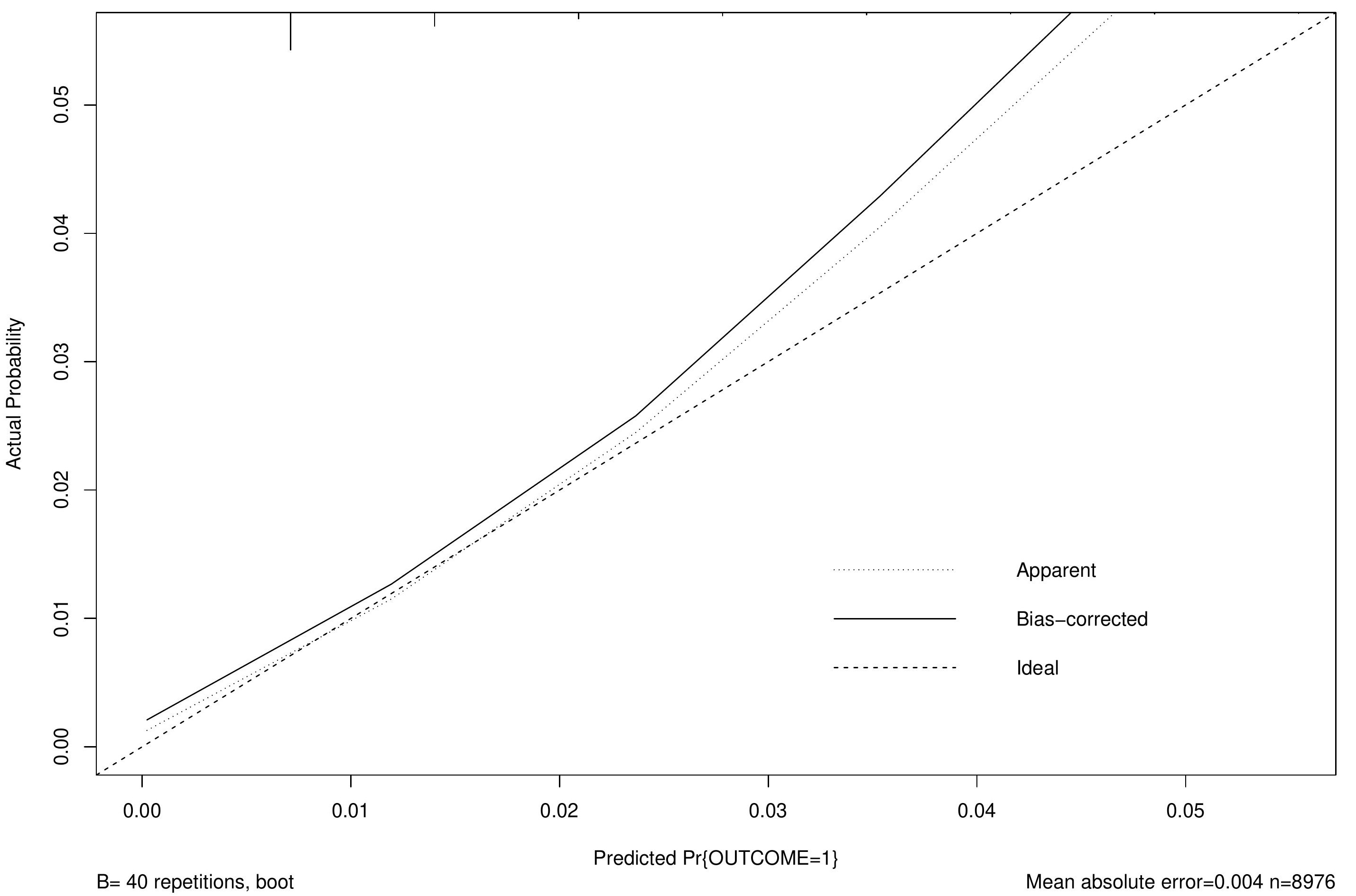


Supplementary Figure 2. Per-protocol representative sample analysis of surgical mortality following elective surgery in high-income, low-middle income, and African countries

$6 \%$

$5 \%$

$4 \%$

$3 \%$

$2 \%$

$1 \%$

$0 \%$

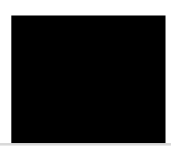

All-cause postoperative mortality

Mortality following postoperative complications

HIC ISOS

- LMIC ISOS

- ASOS

ISOS International Surgical Outcomes Study, ASOS African Surgical Outcomes Study, HIC high income countries, LMIC low-middle income countries 

Supplementary Material

Click here to download Supplementary Material: 27. Supplementary material ASOS outcome definitions.docx

\begin{abstract}
Ch here to download Supplementary Material: 27. Supplementary material AsOS outcome definitions.docx
\end{abstract} (1) 

Supplementary Material
Click here to download S Supplementary Material
Click here to download Supplementary Material: 28. Revision ASOS Lancet STROBE_checklist_cohort.doc

C

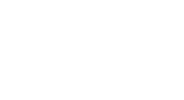

.


(1)

更

更

更

更

更

更

更

更

更

更

更

更

更

更

更

更

更

更

更

更

更

更

更

更

更

更

更

更

更

更 